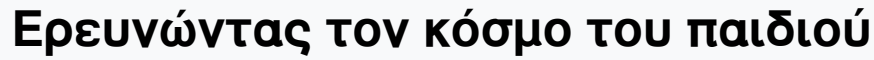

Tó 7 (2007)

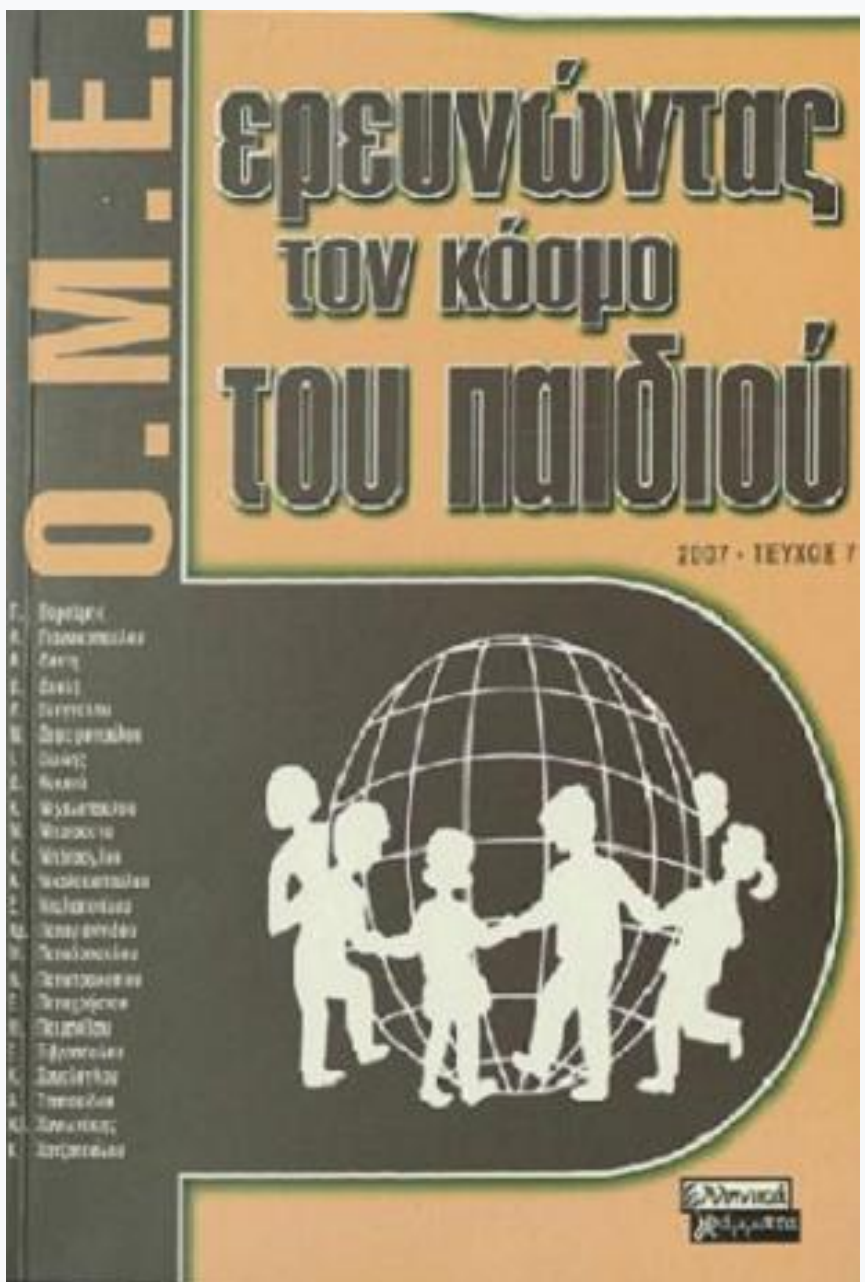

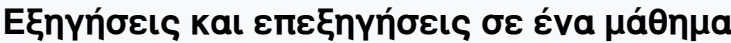

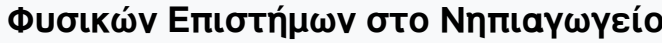

Mapía Пoukvídou (Maria Pimenidou), Mapía

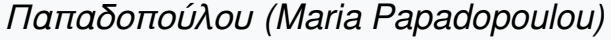

doi: $10.12681 /$ icw.18229

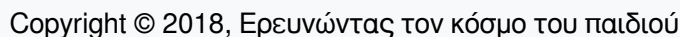

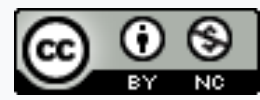

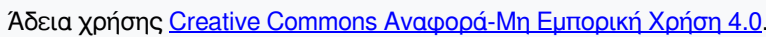

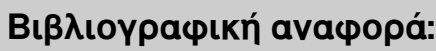

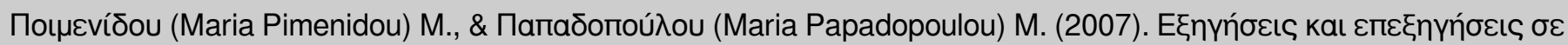

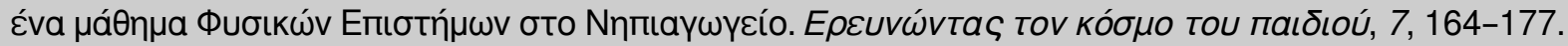

https://doi.org/10.12681/icw.18229 


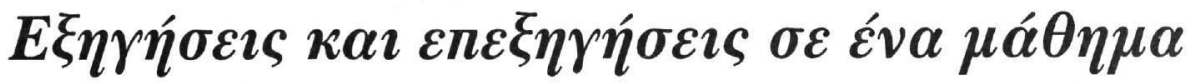

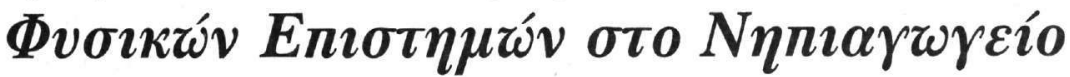

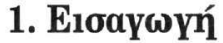

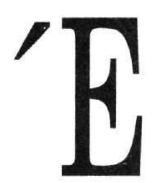

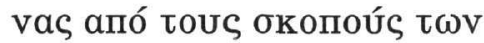

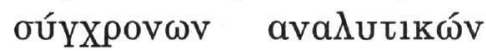

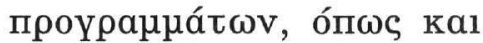

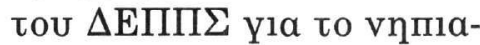

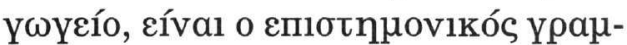

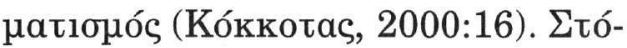

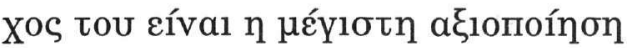

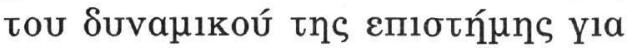

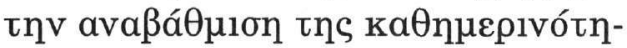

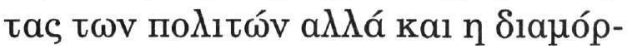


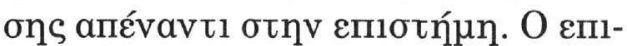

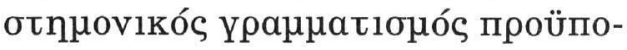

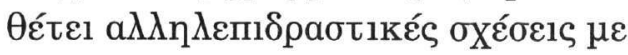

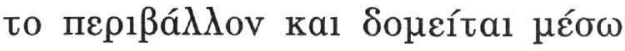

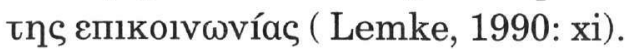

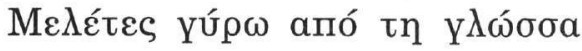

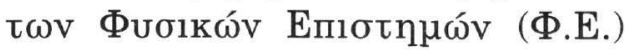

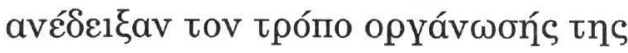

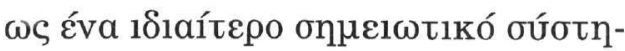

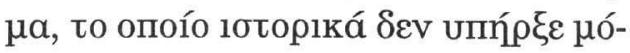

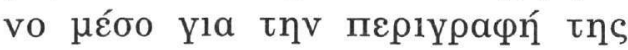

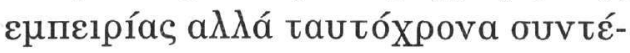

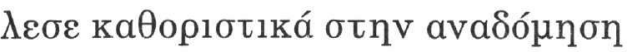

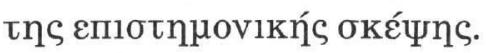

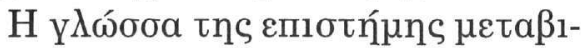

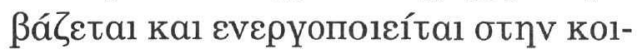

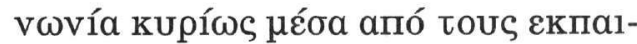

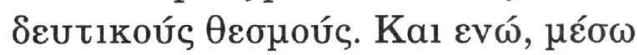

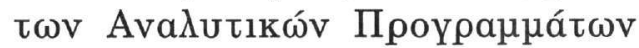

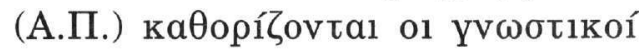

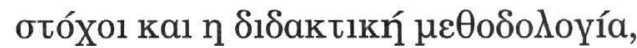

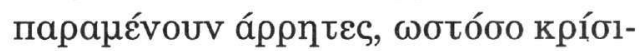

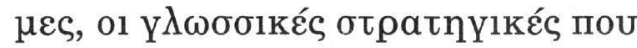

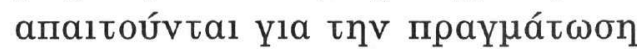

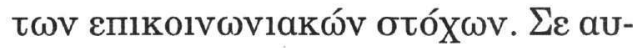

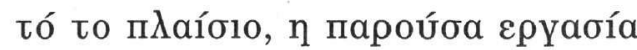
o

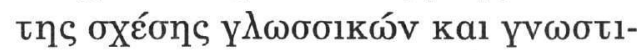

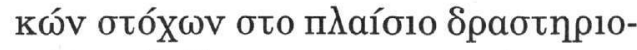

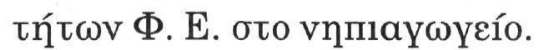

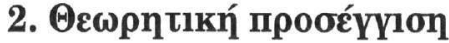

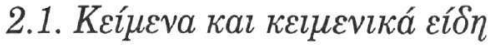

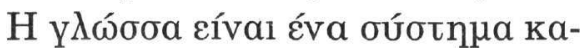

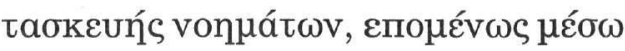

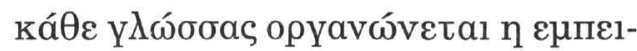

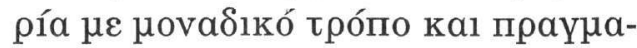

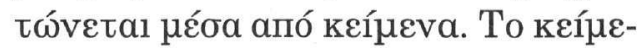

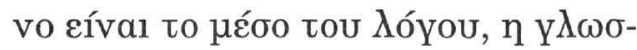

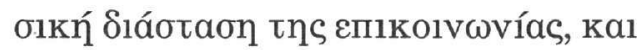

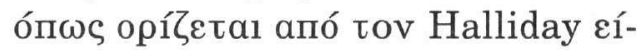
va1: « $\eta \lambda$

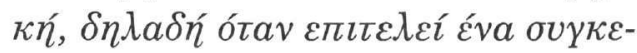




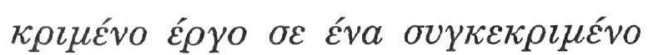

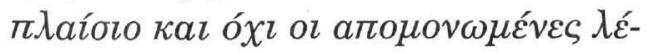

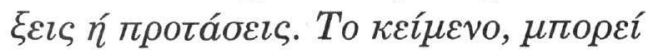

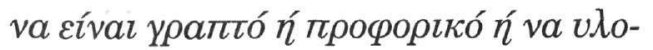

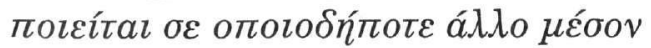

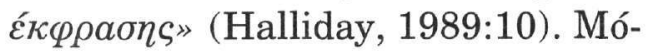

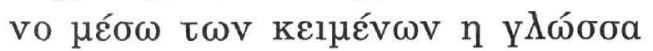

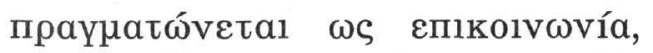

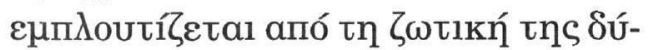

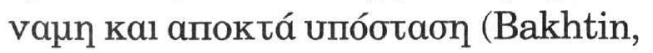

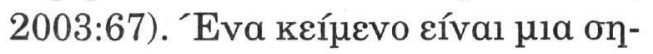

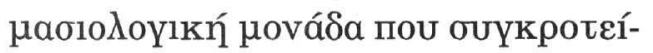

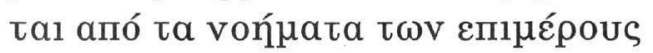

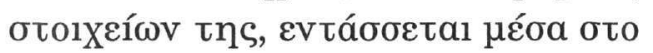

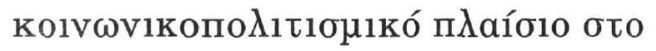
опоі́o пฺарáyetal kal katavoeítal kal

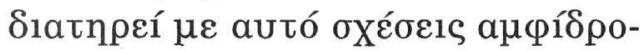

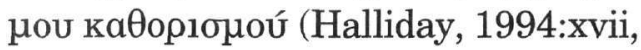
$\Lambda$ úкоч, 2000:62).

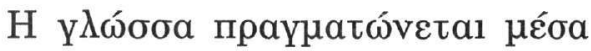

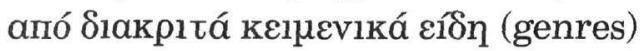

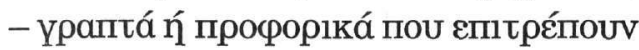

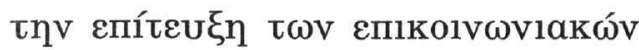

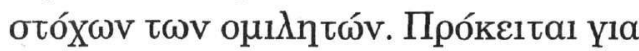

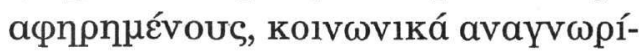

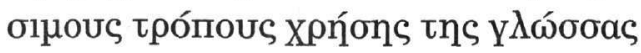
o1 oпоíol eп1 tou Aóyou (Hyland, 2002:114). Av ta

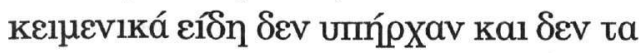

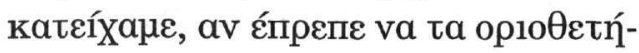

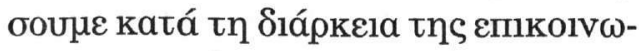

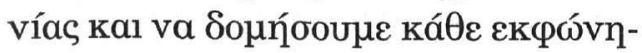

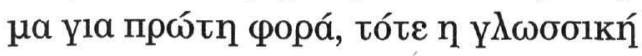

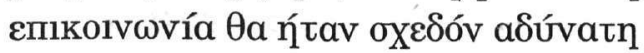

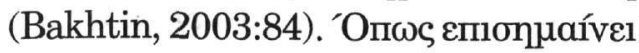

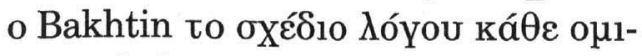

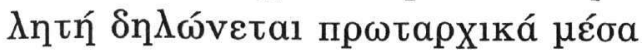

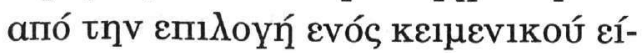

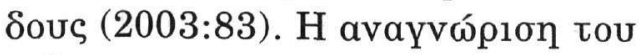

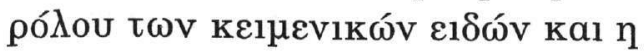

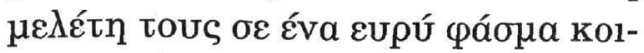

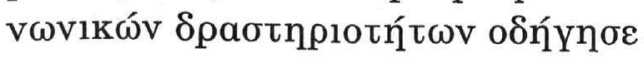

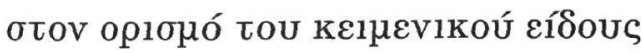

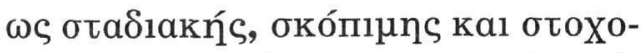

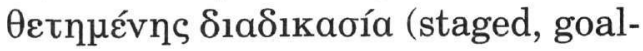
oriented purposeful activity), п опоі́a

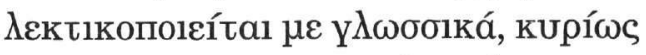

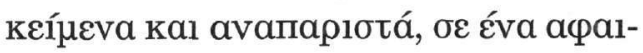

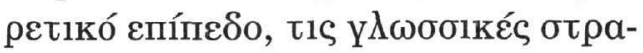

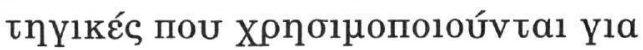

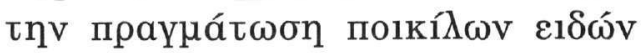

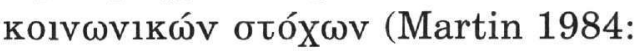

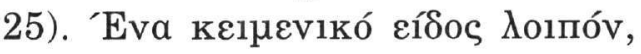

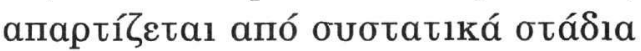

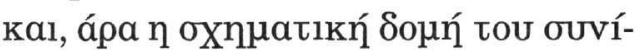

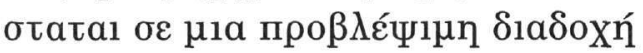

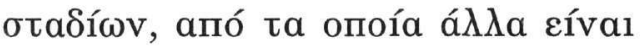

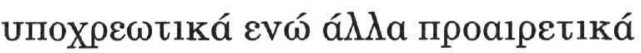
(Macken - Horarick, 2002:20). O pó-

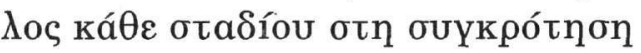

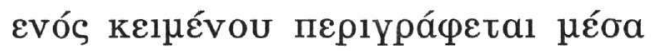

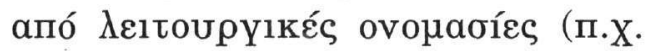

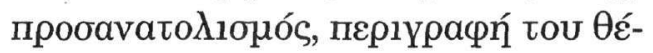

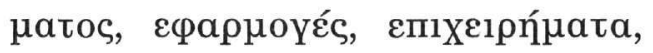

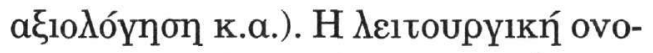

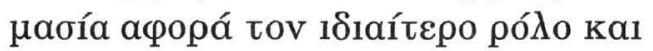

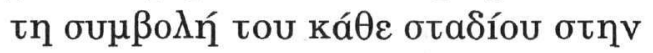

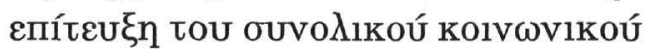

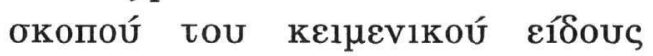
(Eggins \& Slade, 1997:233).

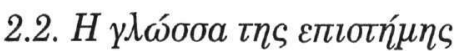

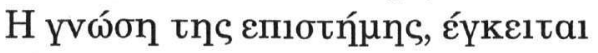

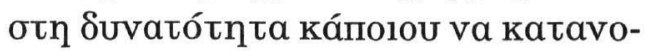

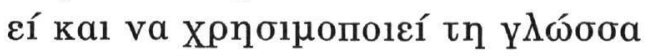

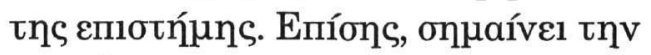

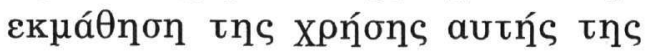

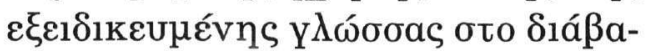

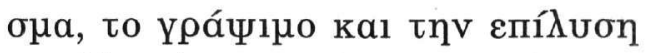

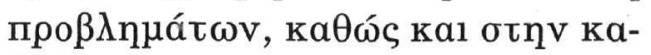

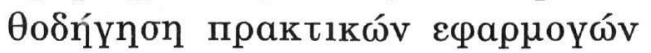

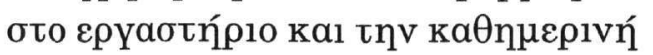

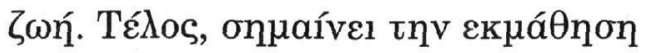

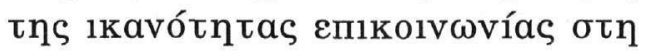




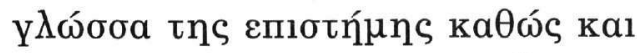

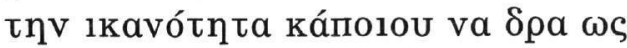

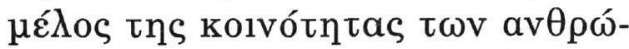

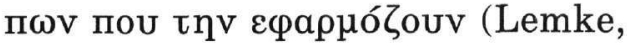

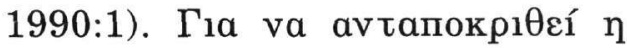

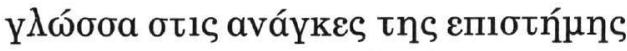

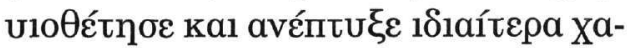

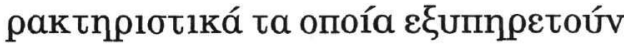

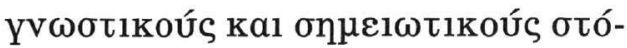

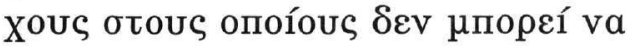

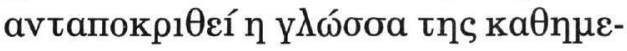

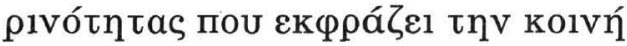

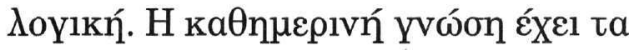

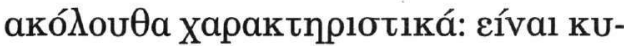

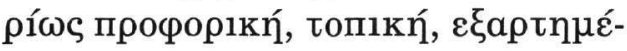

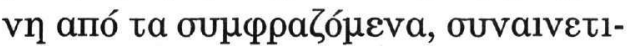

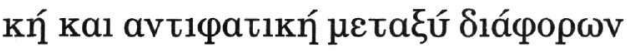

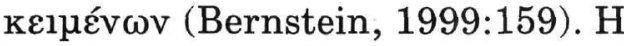

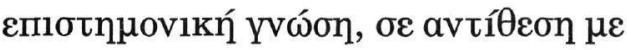

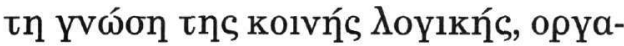

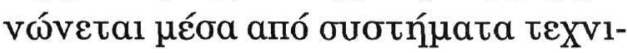

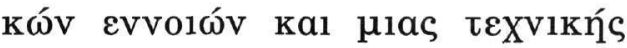

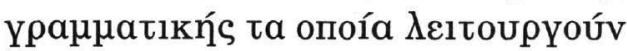

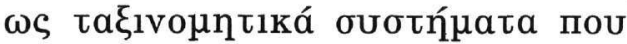

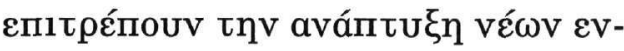

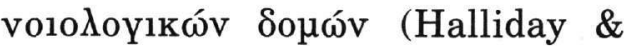
Martin, 2004:34-37).

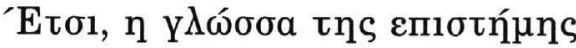

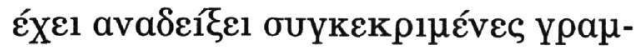

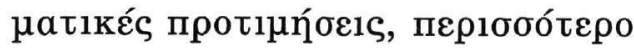

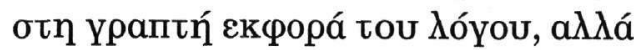

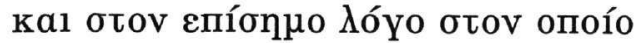

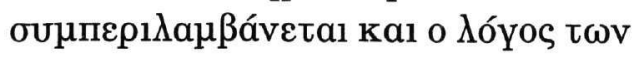

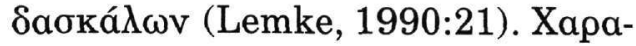

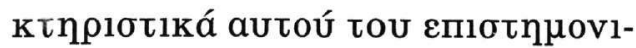

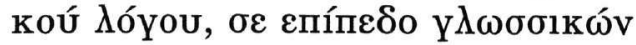

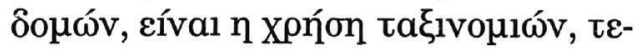

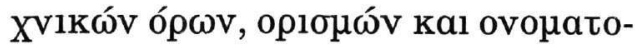
пoínons (Halliday, 2004:137-39. Martin,1992:179-83. Lemke1990:

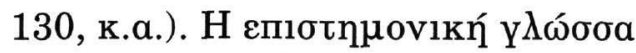

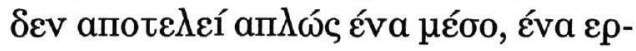

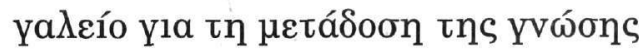

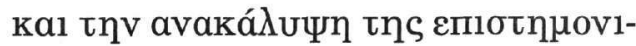

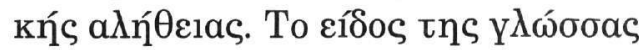

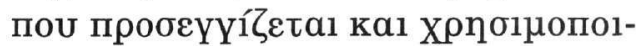

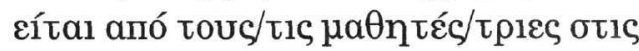

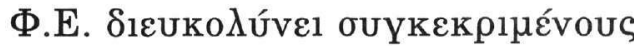

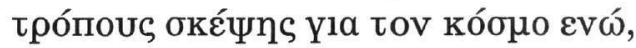

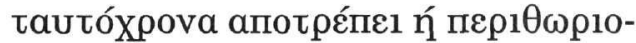
повєí ádAous (Veel, 2000:162). Tau-

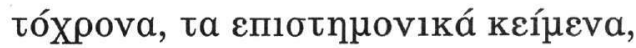

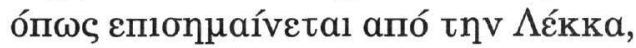

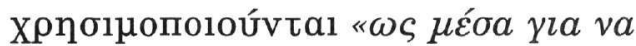

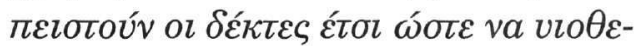

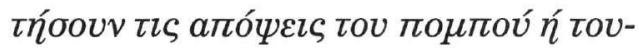

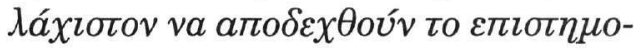

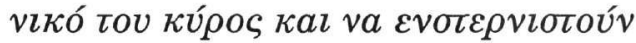

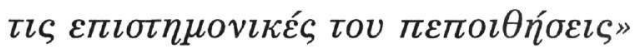
(

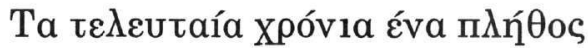
$\mu \varepsilon \lambda \varepsilon \tau \omega$ v a

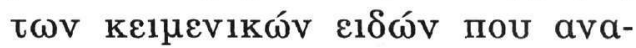

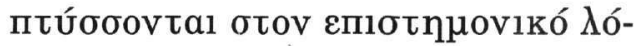

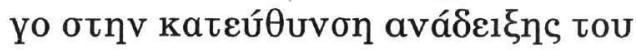

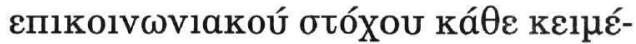
vou (Martin, 1992. Macken-Horarik, 2002. Christie, 1997. Veel, 2000,

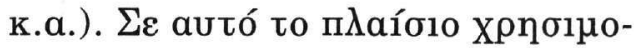

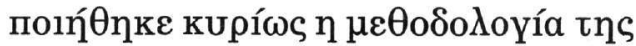

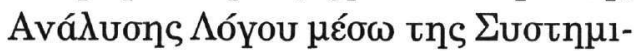

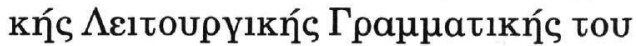

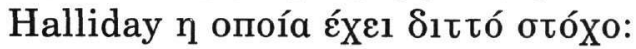

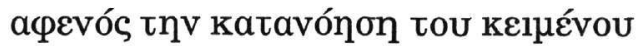

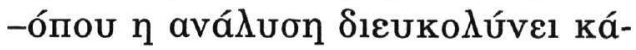

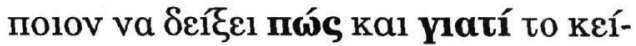

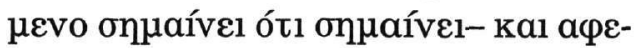

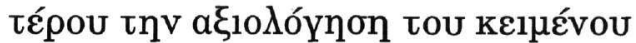

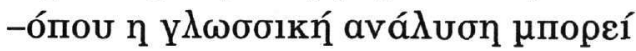

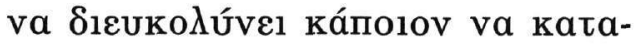
vońбe1 tous hóyous yia tous onoíous

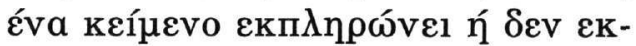

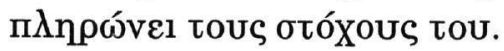

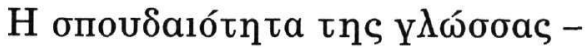




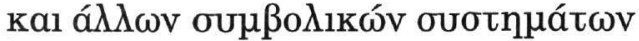

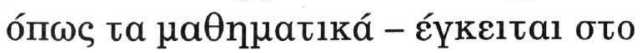

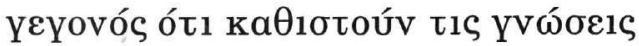

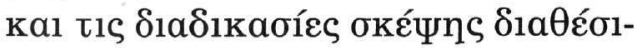

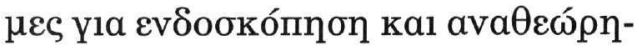

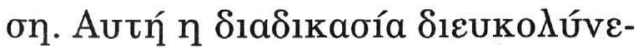

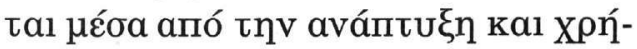

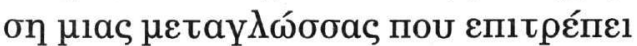

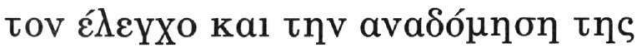

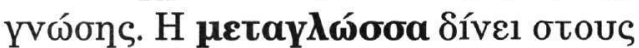

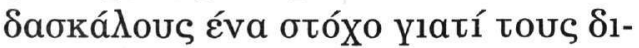

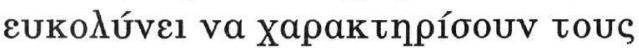

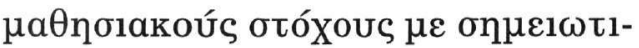

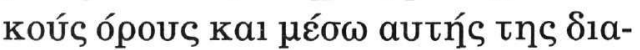

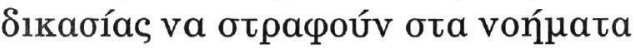
(Macken-Horarik, 2002:18). Апó

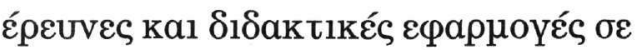

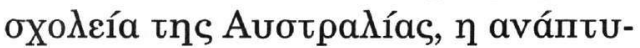

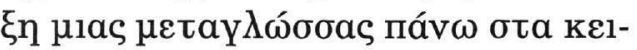

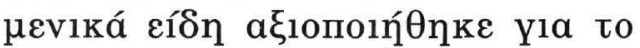

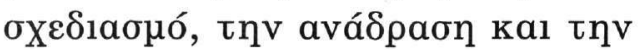

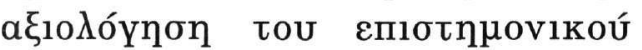

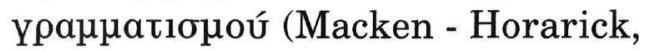
2002:18).

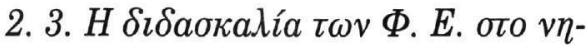

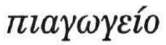

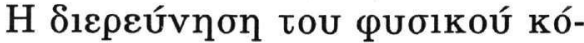

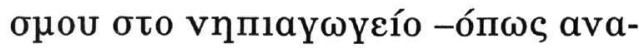

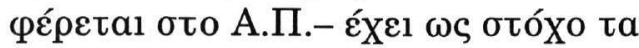
vท́mia va katavooúv,

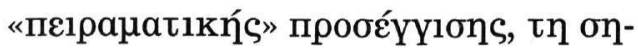

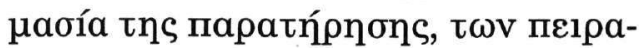

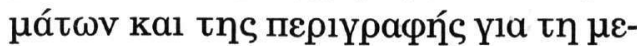

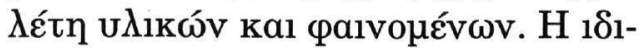

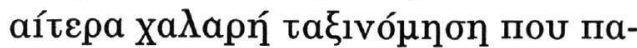

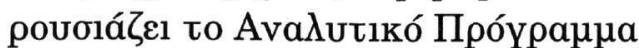

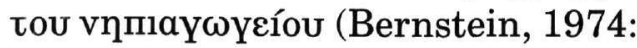

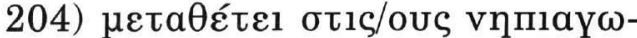

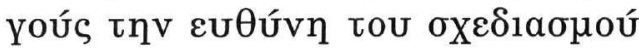

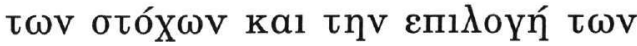

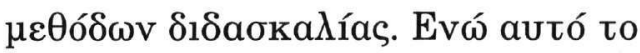

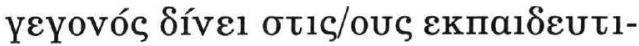

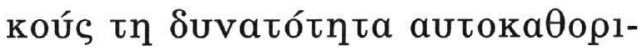
opoú kal autovopías évavtl tns

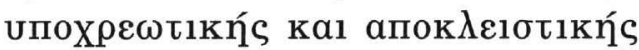

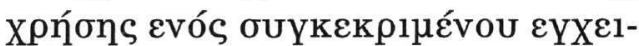

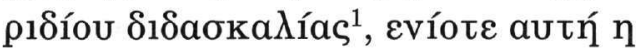

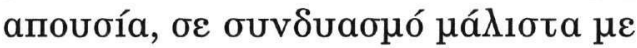

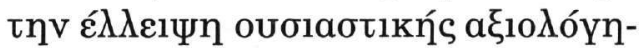

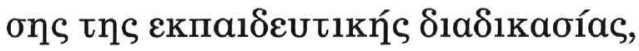

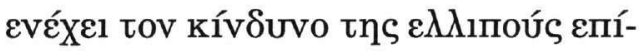

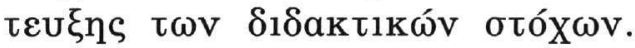

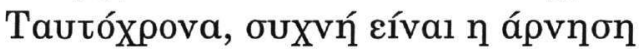

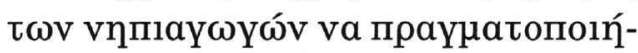

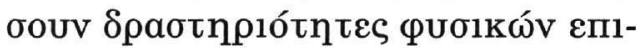

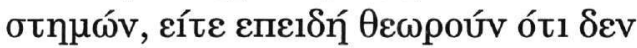

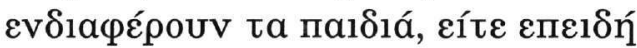

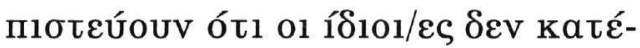

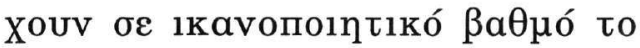

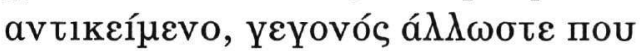

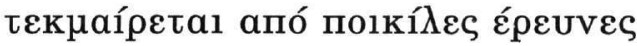

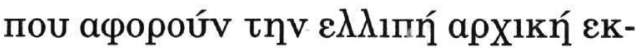

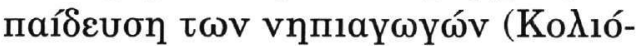

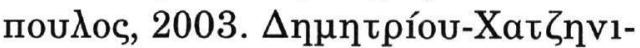

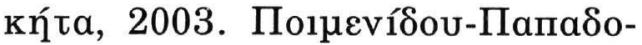

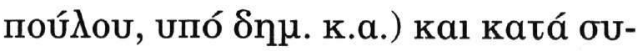

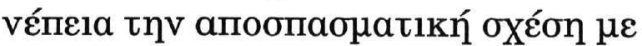

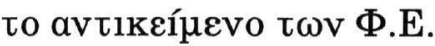

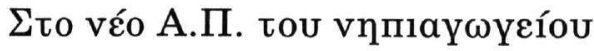

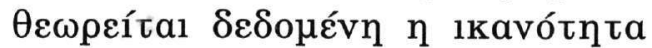

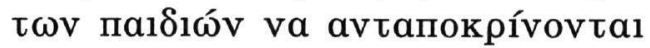

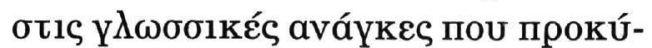

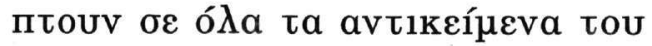

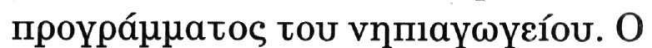

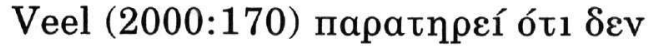

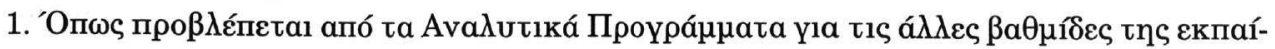

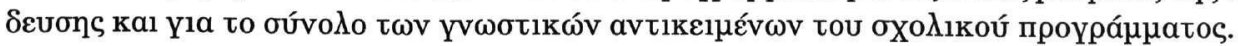




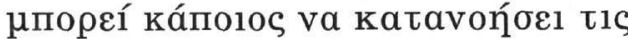

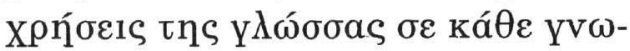

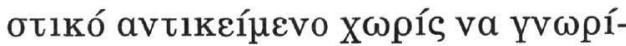

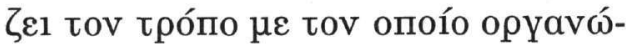

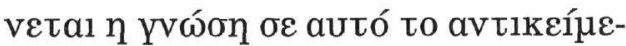

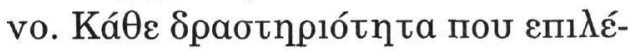

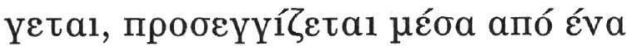

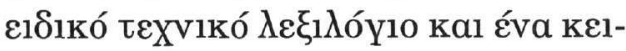

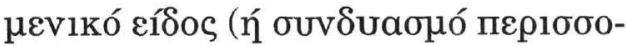

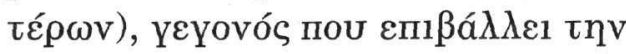

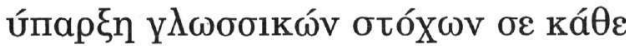

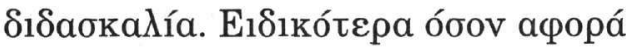

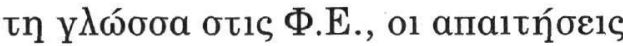

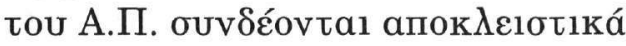

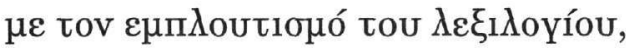

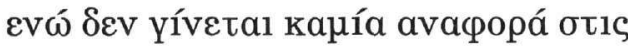

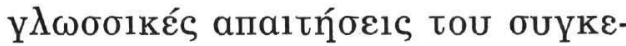

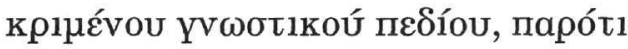

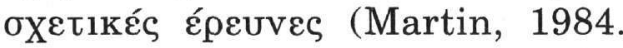

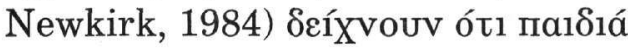

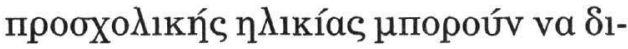

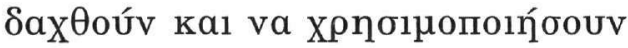

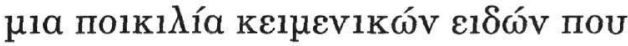

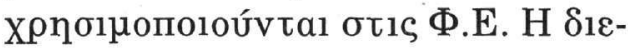


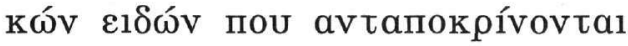

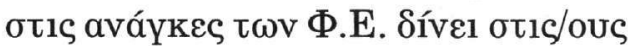

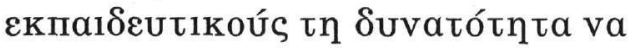

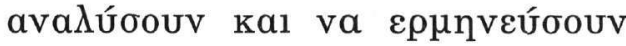

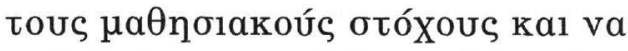
$\mu \varepsilon \theta 0 \delta \varepsilon u ́ \sigma o u v$ 七n $\delta 1 \delta a \sigma k a \lambda i ́ a ~ \mu \varepsilon ́ \sigma \omega$

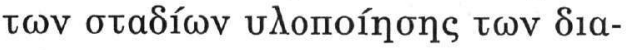

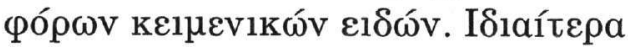

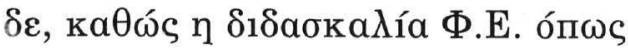

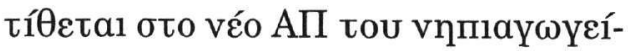

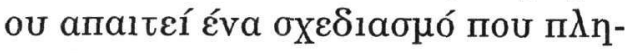

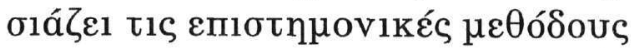
(Tsatsaroni, Ravanis \& Falaga,

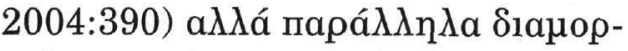

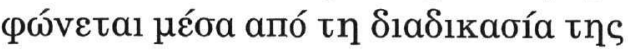

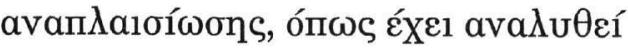
anó тov Bernstein (1990:183-4).

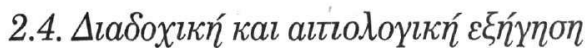

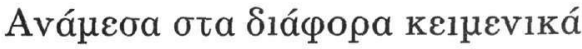

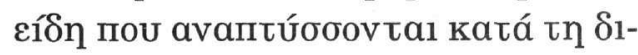

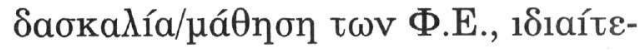

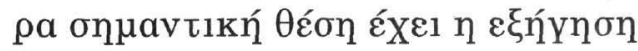

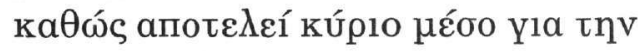

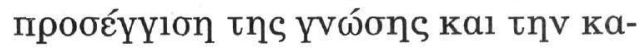

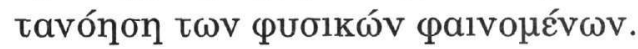

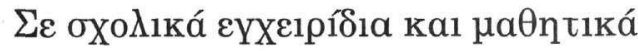

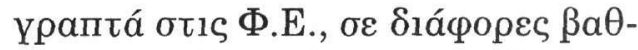

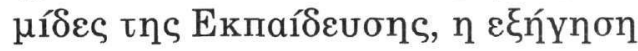

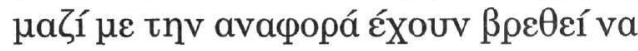

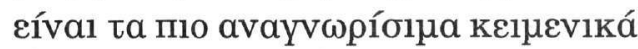

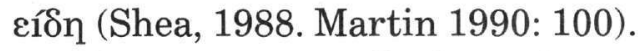

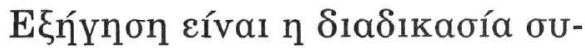

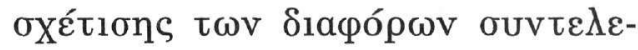

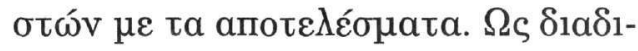

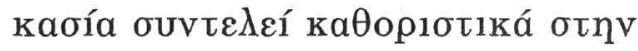

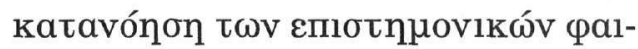

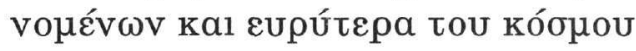

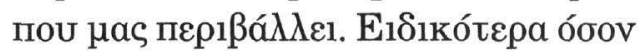

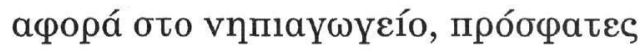
épeuves (Carey, 1985. Christidou \&

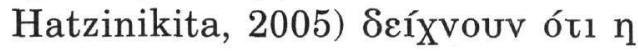

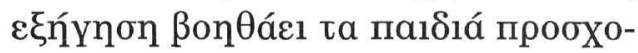

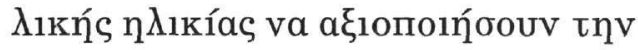

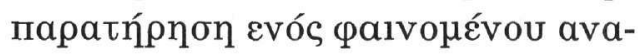

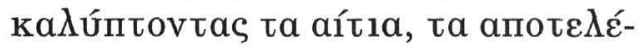

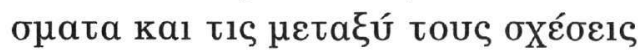

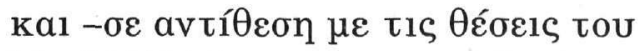

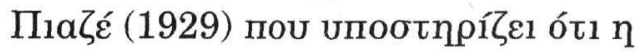

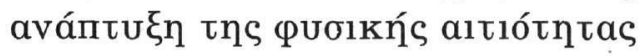

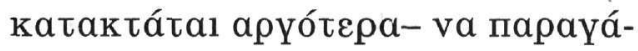

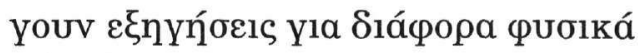

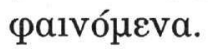

$\Sigma u ́ \mu \varphi \omega v a \mu \varepsilon$ to Veel (2000:172), n

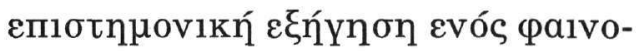

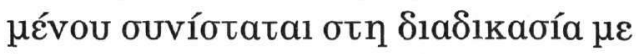

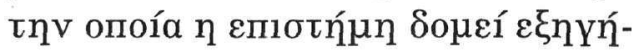

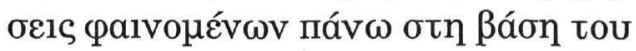

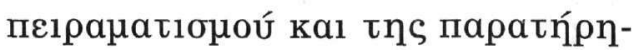

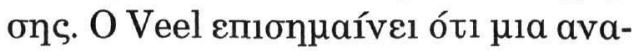




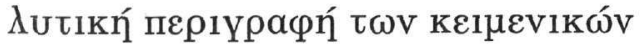

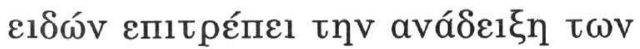

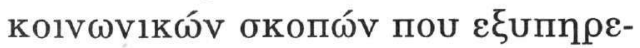

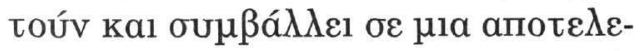

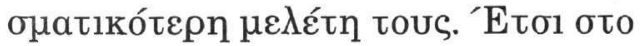

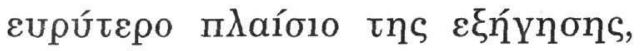

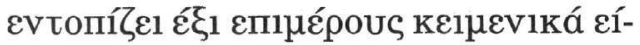

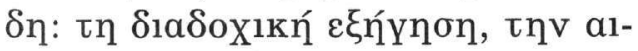

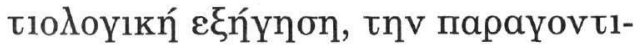

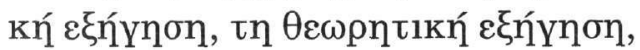

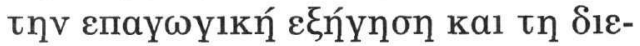

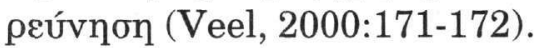

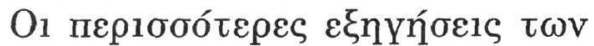

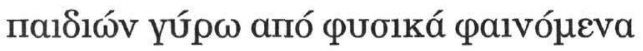

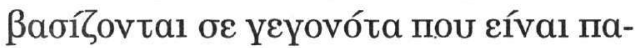
ратпри́бıна. Парá $\lambda \lambda \eta \lambda \alpha$, та паıßı́́

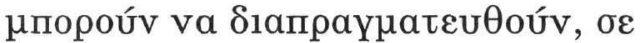

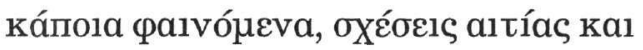

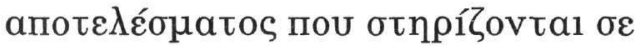

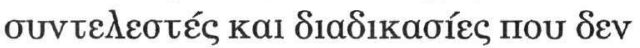

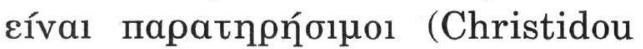

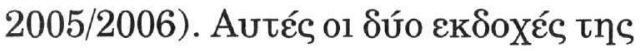

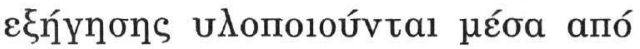

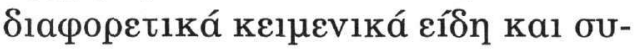

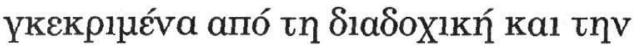

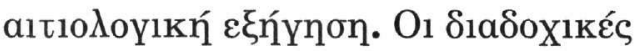

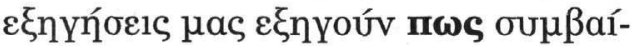

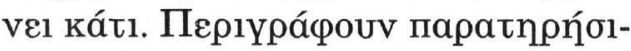

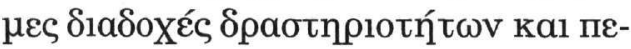

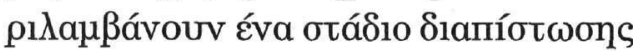

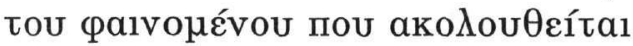

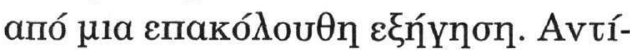

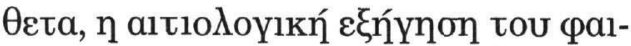

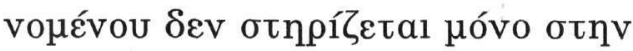

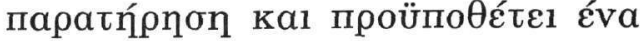

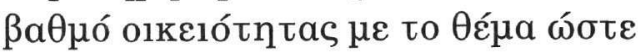
va avantuX $\theta \varepsilon i ́$ to oXetikó evvoioגo-

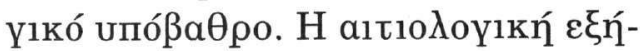

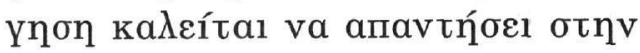

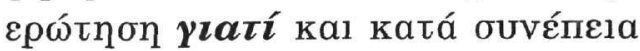

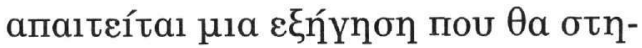

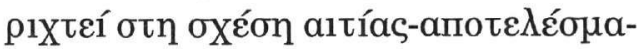

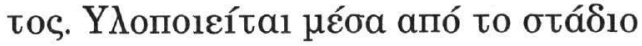

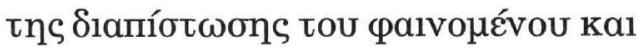

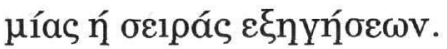

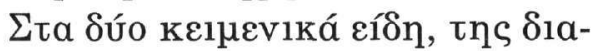

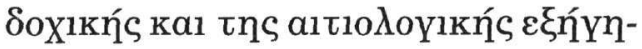

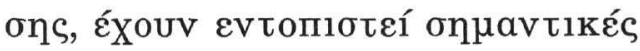

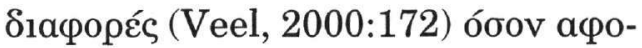

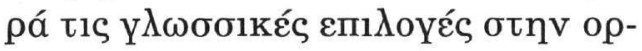

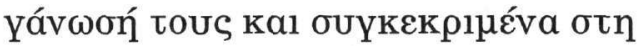
$\lambda \varepsilon \xi 1 k \eta ́$ пUкvó́

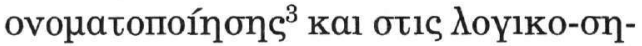

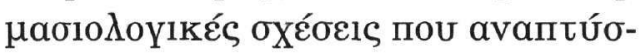

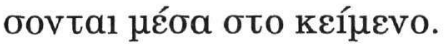

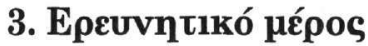

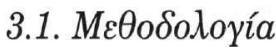

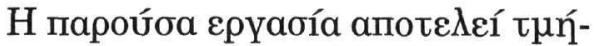

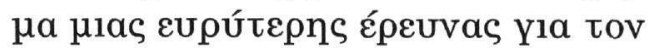

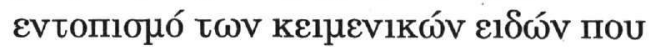

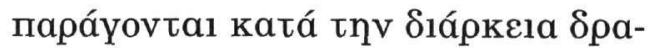

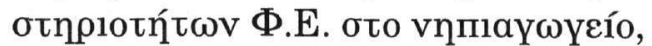

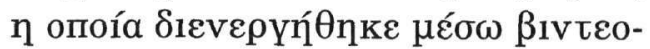

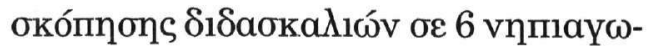
yeía tou Nouoú Mayvnoíac kal tou

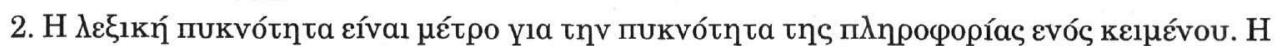

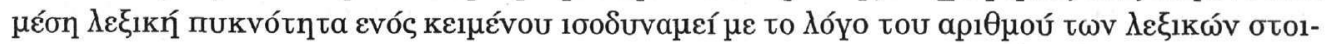

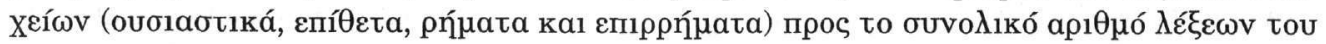

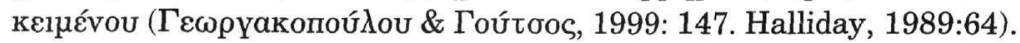

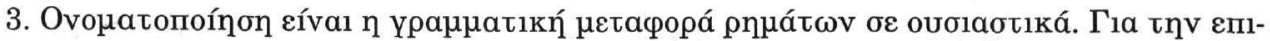

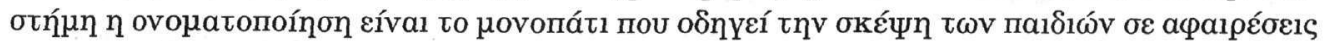

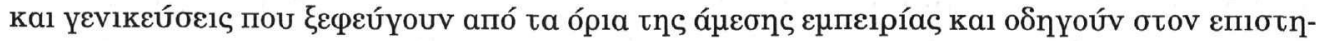

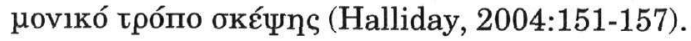


Nopoú Attıkńs (Má1os 2004 -Máıos

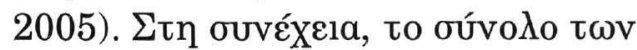

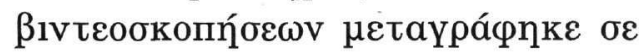

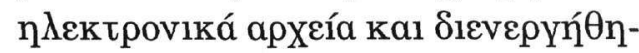

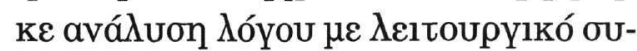

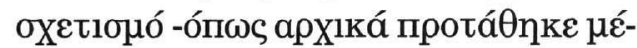

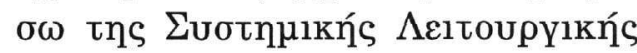
Грациатıки́s tou M.A.K. Halliday каı

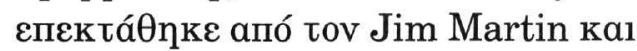
touৎ ouvepyátes tou.

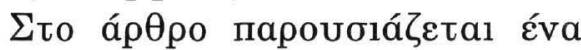

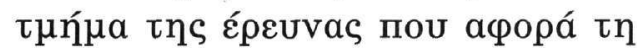

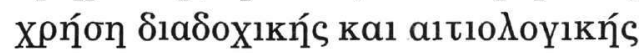

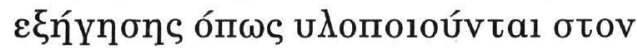

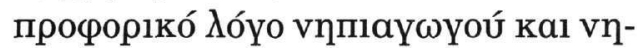

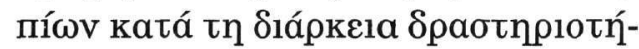

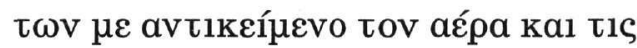

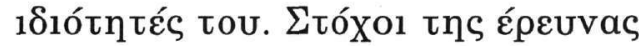

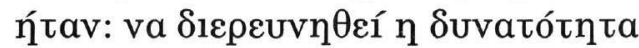

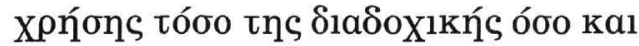

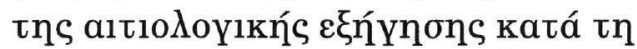

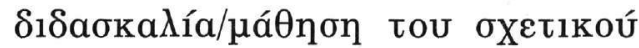

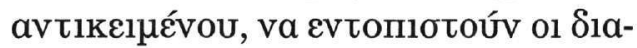

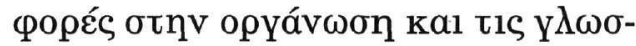

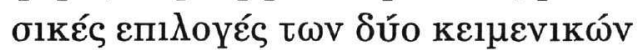

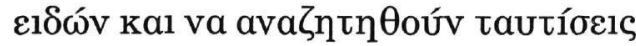

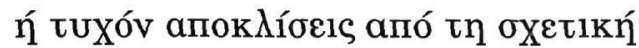

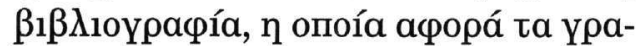

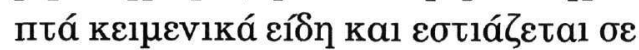

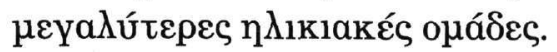

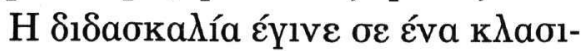

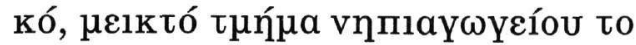

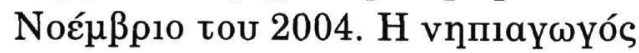

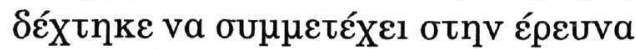

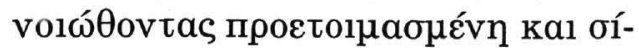

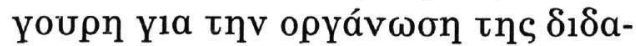

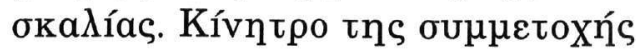

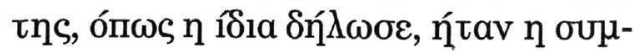

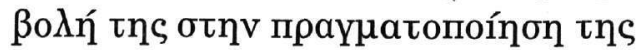

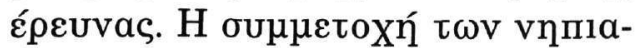

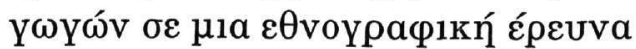

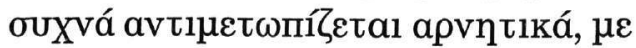

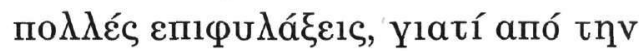

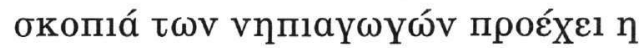

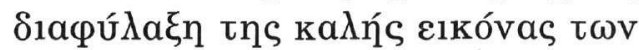

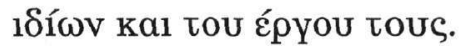

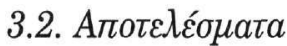

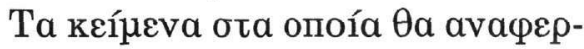

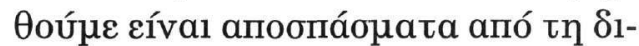

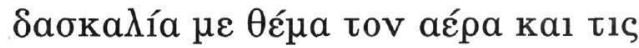

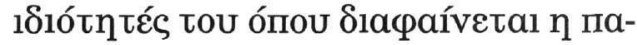

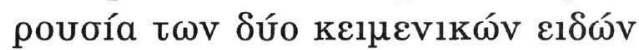

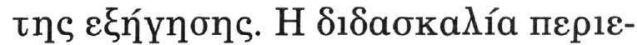

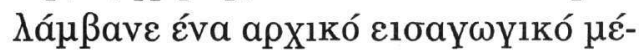

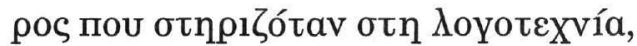

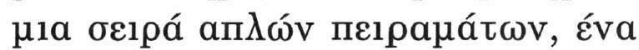

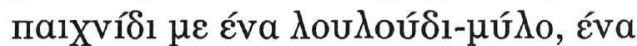

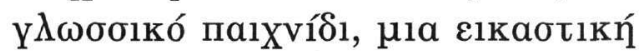

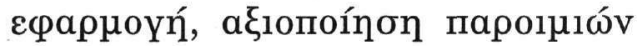

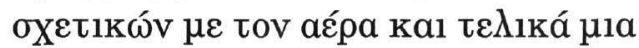

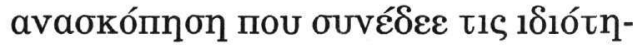

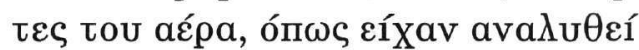

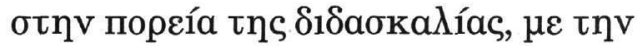

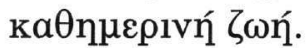

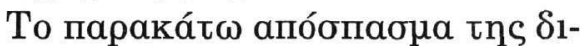

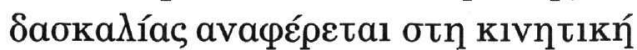

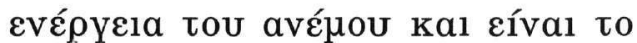

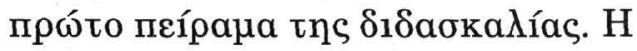

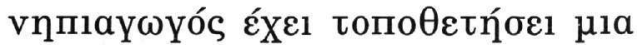

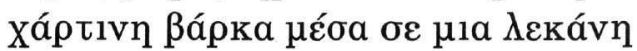

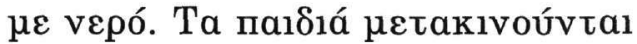

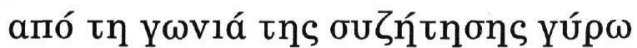

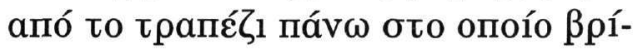

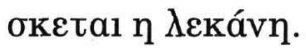

\section{Ké́pevo 1}

$\mathrm{N}$ :

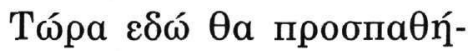

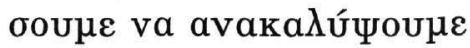

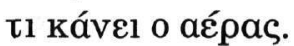

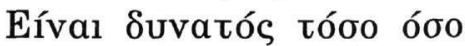

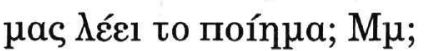

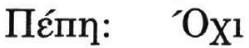




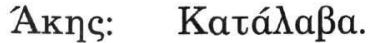

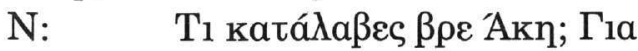

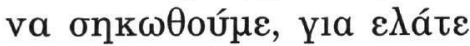

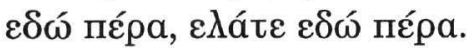

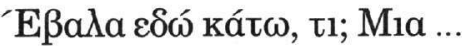

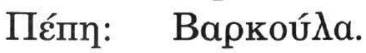

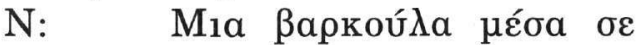
$\mu 1 \alpha \ldots$

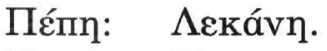

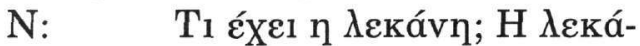

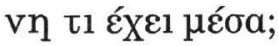

OM: Nepó.

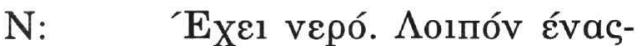
Évas $\theta \varepsilon ́ \Lambda \omega$ va пробпаӨń-

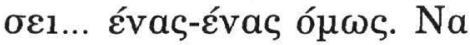

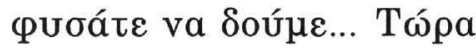

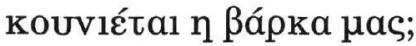

OM: $\quad \mathrm{OXX}^{1}$

Avópéac: $\mathrm{Nal}$

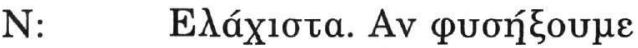

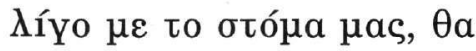

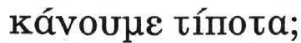

'Aкпя: 'OX1.

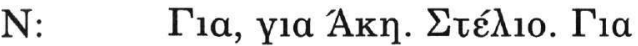
甲úoa.

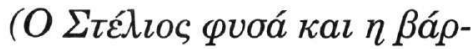
$\kappa a \mu \varepsilon \tau a \kappa \imath v \varepsilon i ́ \tau a \imath)$

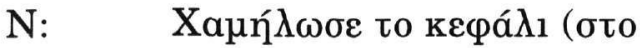

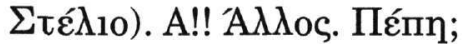

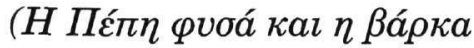

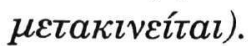

$\mathrm{N}: \quad$ AגAos;

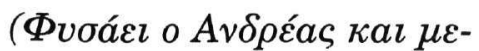

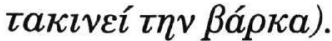

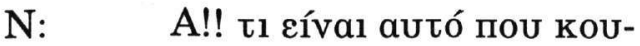
váeı тn ßápka;

Akns: $\mathrm{O}$ aع́pas.

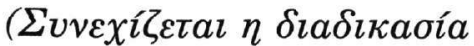

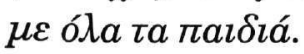

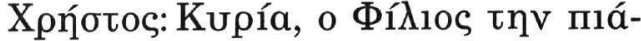
ve1.

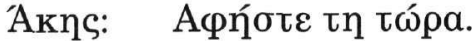

$\mathrm{N}$ : $\quad \mathrm{O}$ aépas eíval autós nоu

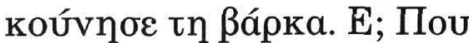

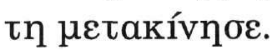

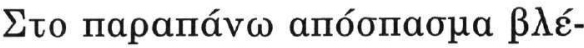

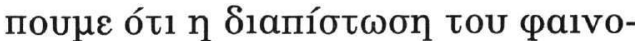

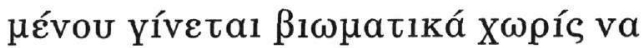

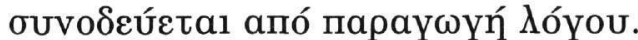

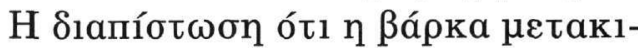

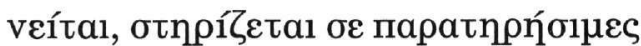

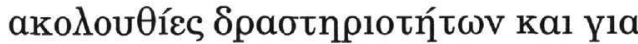

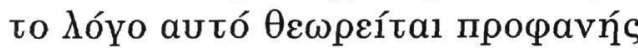

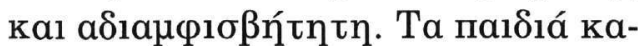

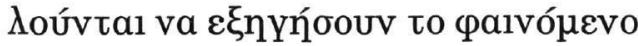

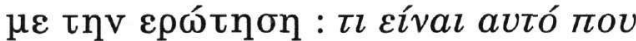

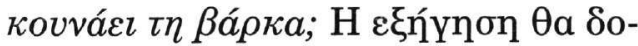

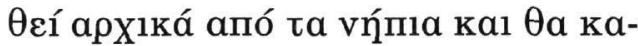

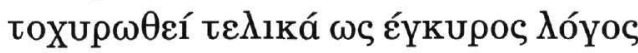

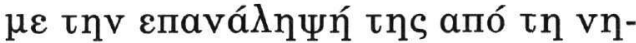

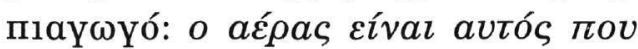

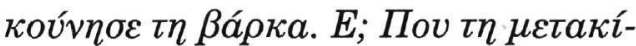

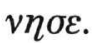

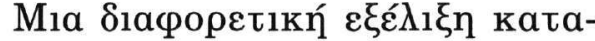

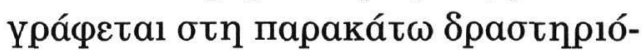

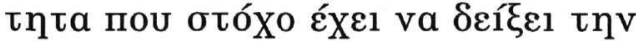

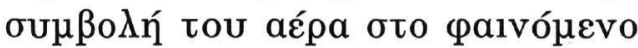
七ns kaúons.

\section{Keípevo 2}

$\mathrm{N}$ :

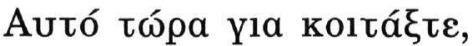

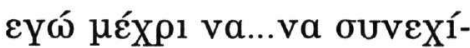

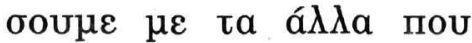

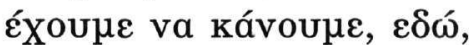

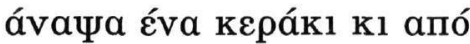

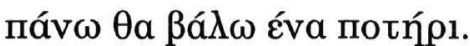

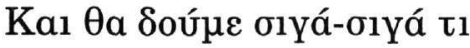
$\theta$ a Yível.

Akns: $\quad$ Aпó пáv 


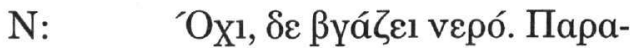

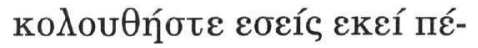
$\rho \alpha \ldots$

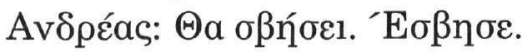

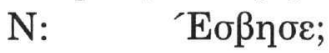

Avôṕ́aç: Nal

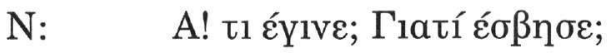

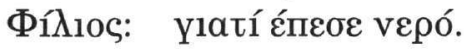

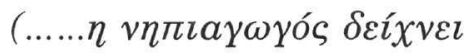

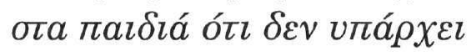
veрó ото поти́рл.

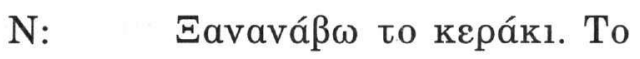

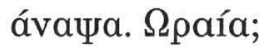

OM: Nal

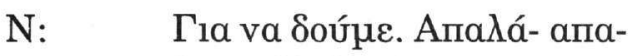

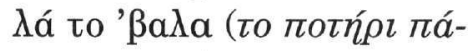

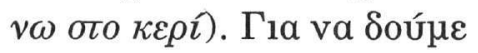
七ı $\theta$ a kóveı.

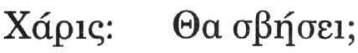

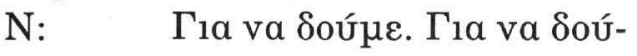
$\mu \varepsilon$.

Xápıc: $\quad \Sigma \beta\lceil ́ v \varepsilon 1$.

Aknc: $\quad$ Aqoú náve ólo1 kovtá.

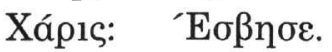

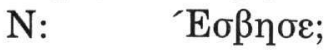

Гıю́руос: Еíxe aع́pa.

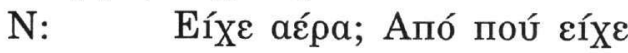

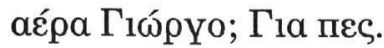

Гıю́руос: 'Еßүаגє то....

Xápns: Kanvó.

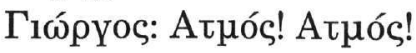

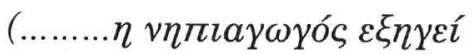

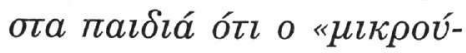

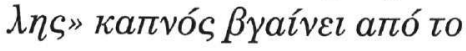

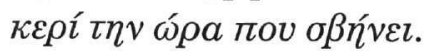

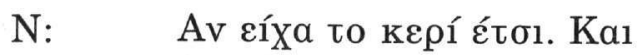

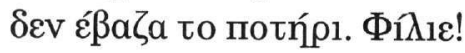

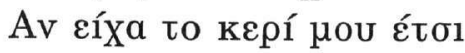

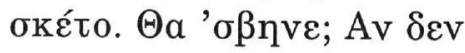

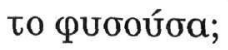

OM: $\quad \mathrm{OX}^{1}$.

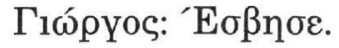

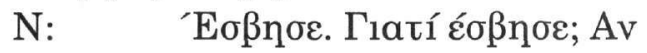

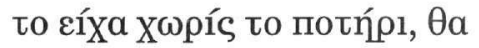

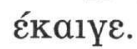

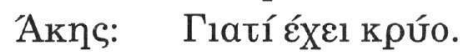

$\mathrm{N}: \quad$ T1' autó $\operatorname{lec} ; \mathrm{Ma} \delta \varepsilon v$ akou-

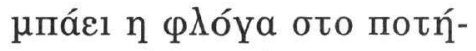
р1. ( ...) $\Delta$ Úokoגo eívaı autó, $\varepsilon$;

Aknc: $\mathrm{M \mu}$...

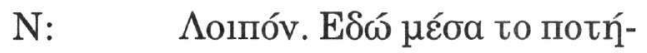

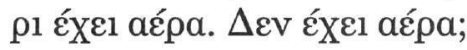

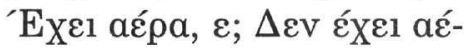

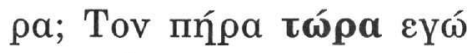

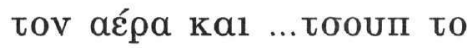

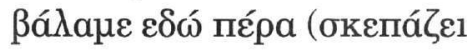
七о кері́ $\mu \varepsilon$ то поти́р1). H

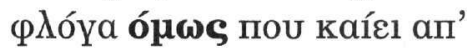

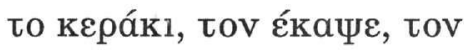

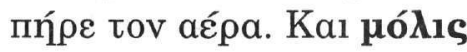

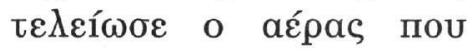

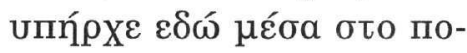

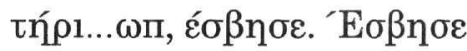
$\eta \varphi \omega \tau i ́ \tau \sigma a$.

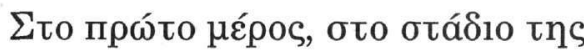
avayvẃpıons tou paivouévou, ta

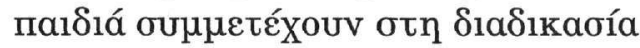

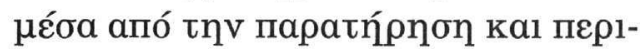

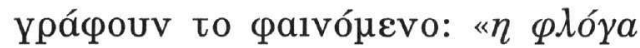

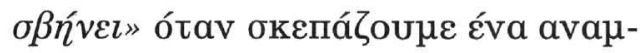

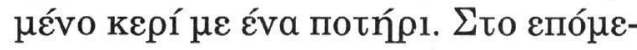

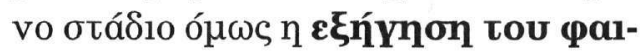

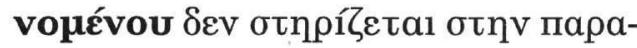

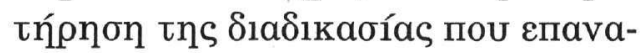

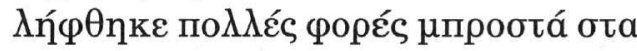

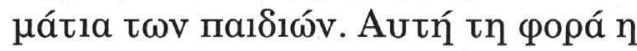

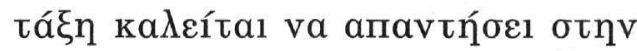

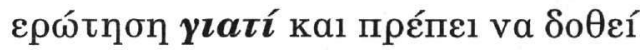

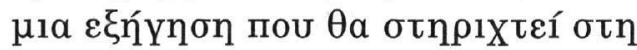

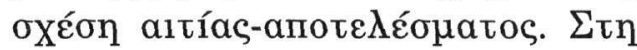




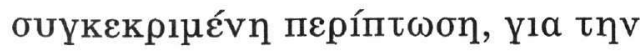

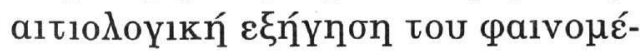

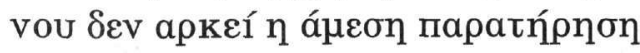

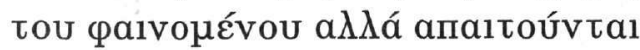

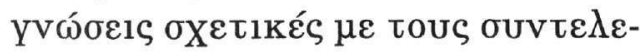

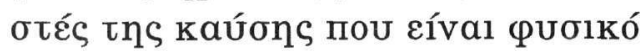

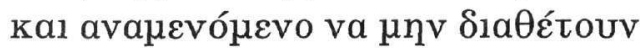
七a víma.

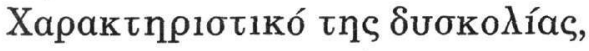

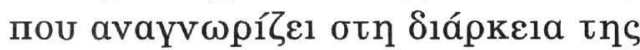

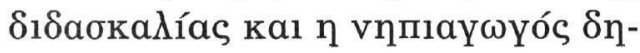

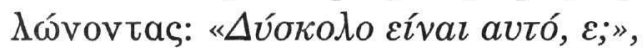

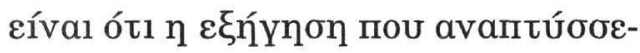

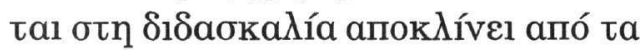

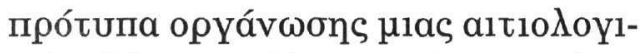

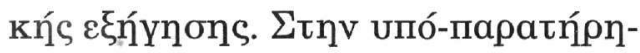

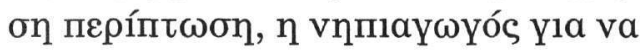

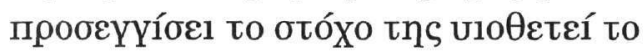

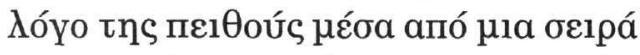

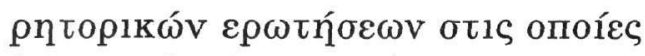

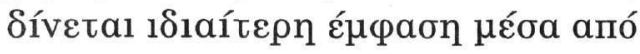

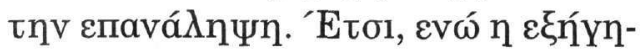

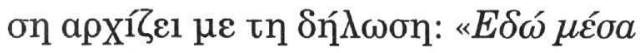

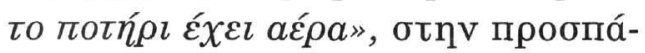

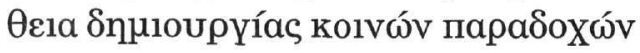

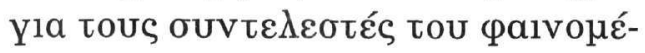

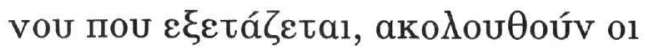

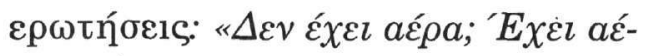

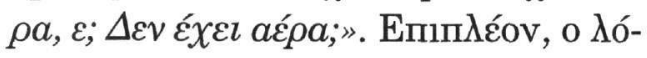

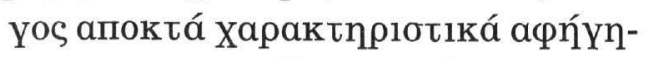

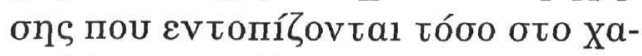
$\mu \eta \lambda$ ќ́ каl чпо $\beta \lambda \eta$ tıкó tóvo 七nৎ $\varphi \omega$ -

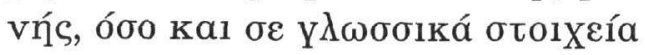

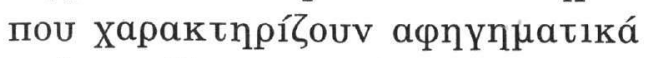

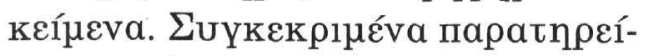

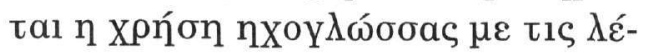

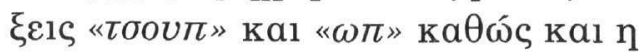

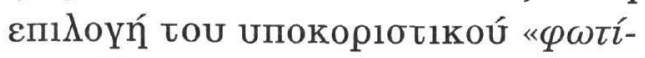

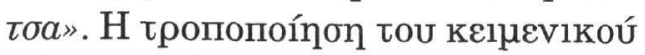

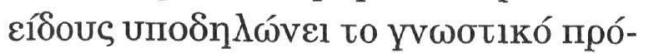

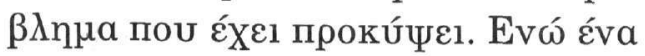

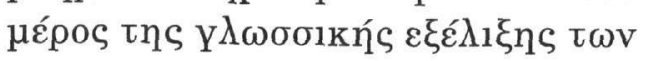

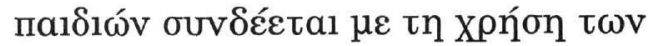

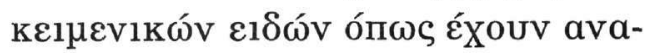

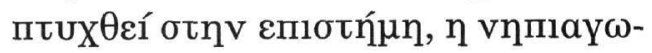

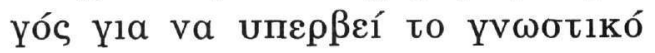

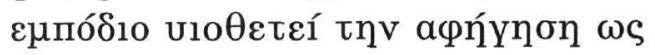
tov t

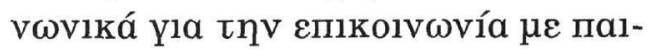

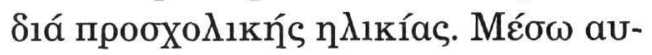

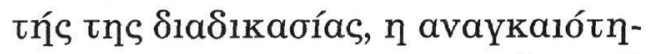

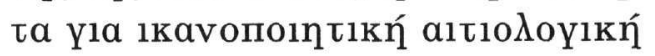

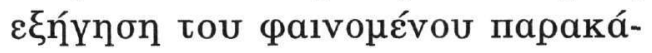

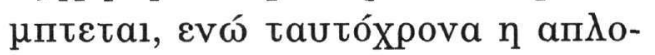

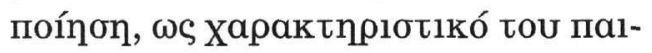

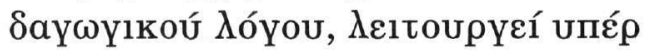

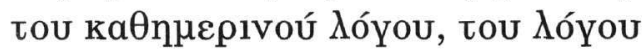

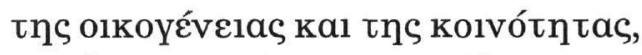

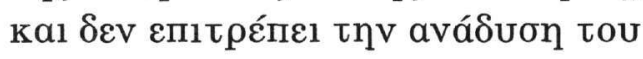

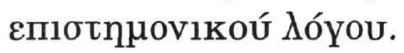

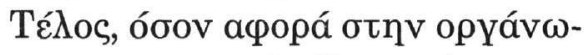

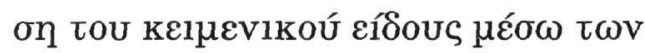

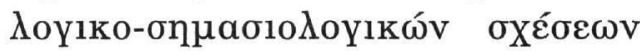

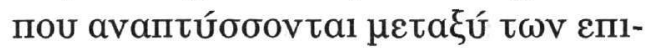

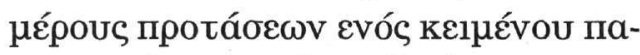

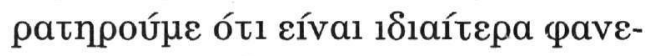

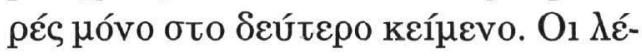

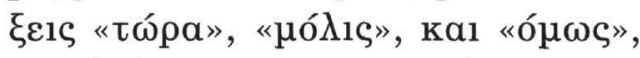

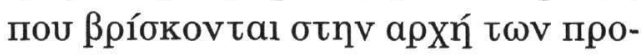

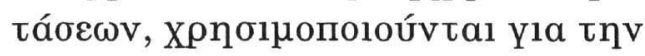

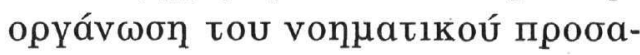

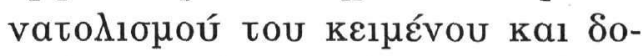

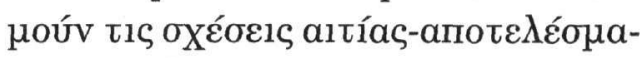

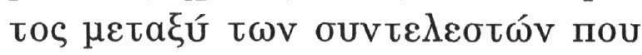

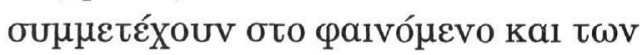

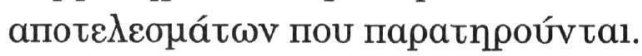

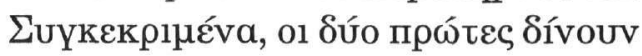

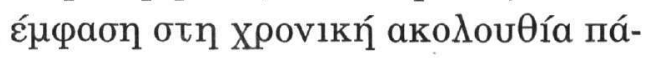

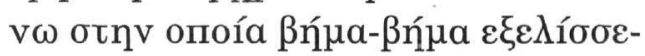

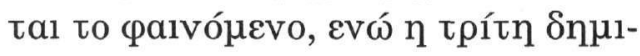

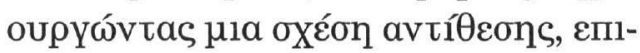

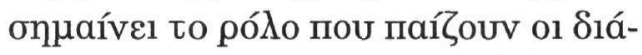

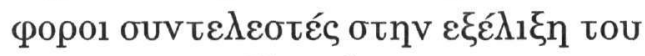

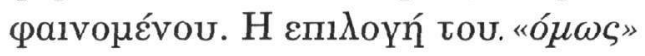




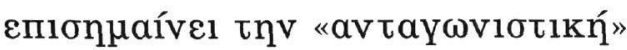

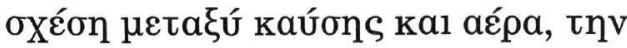

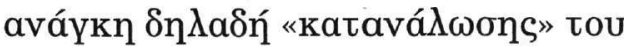

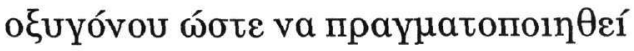
п каúon.

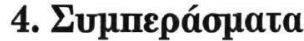

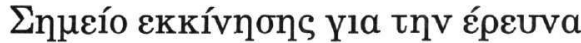

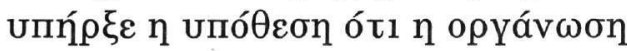

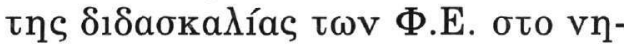

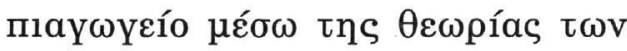

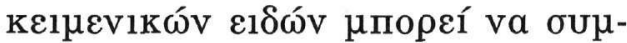

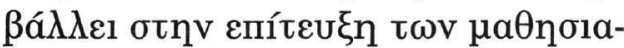

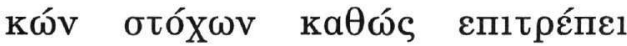

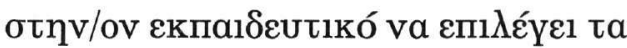

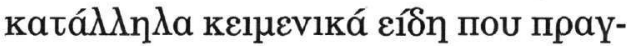

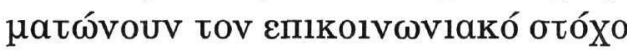

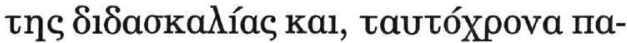

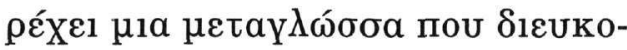

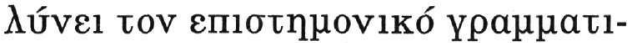

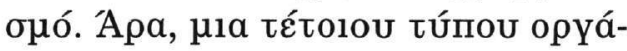

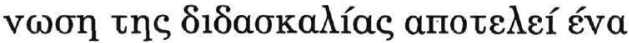

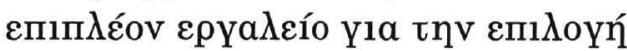

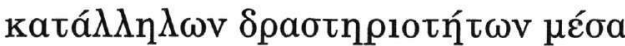

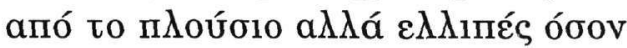

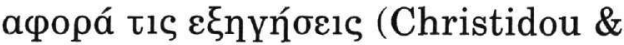

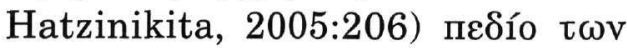

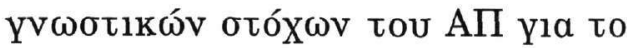

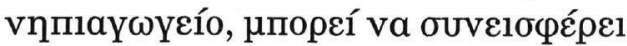

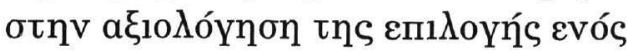

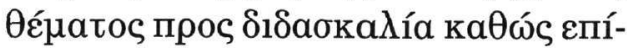

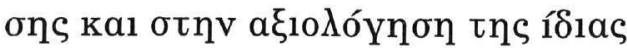

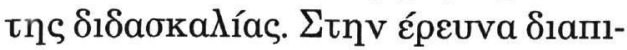

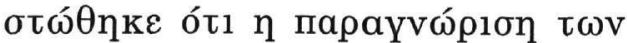

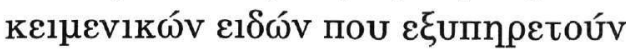

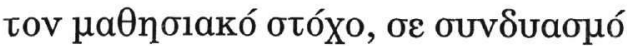

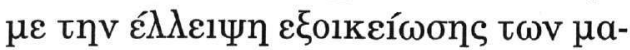

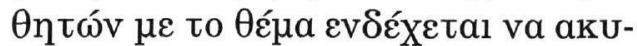


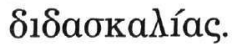

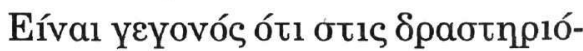

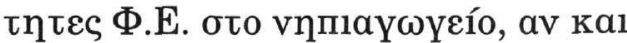

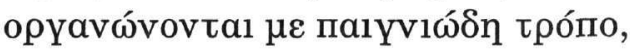

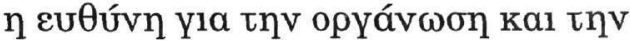

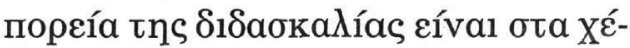

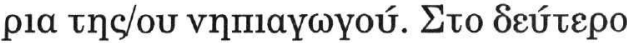

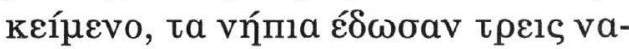

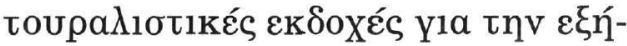

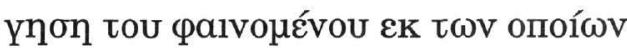

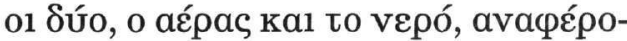

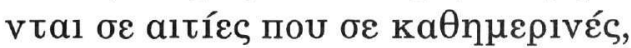

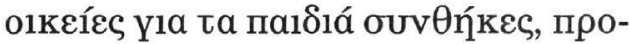

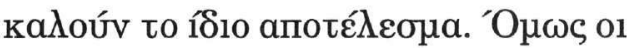

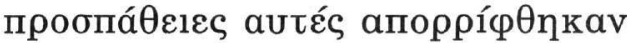

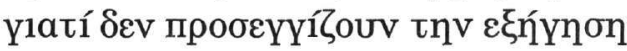

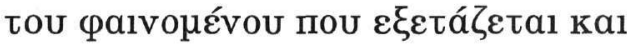

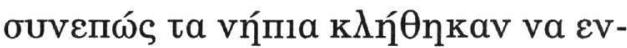

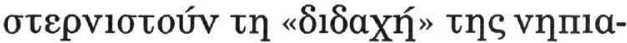
ү

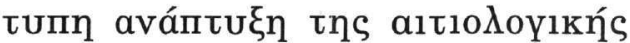

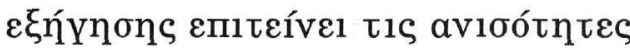

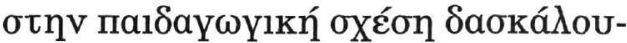

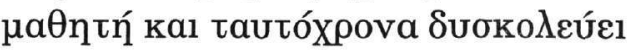

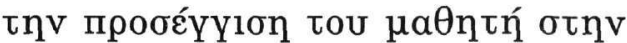

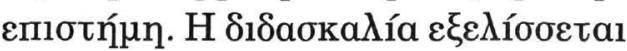

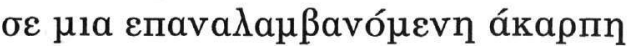

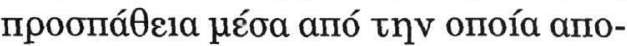

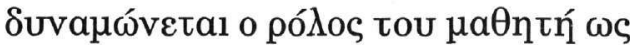

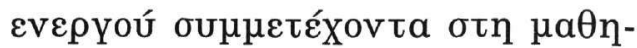

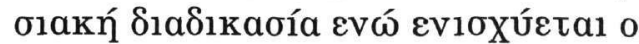

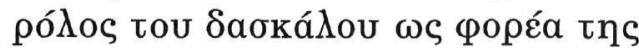

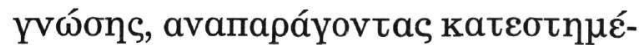

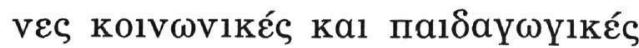

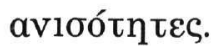

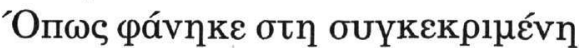

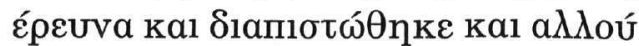

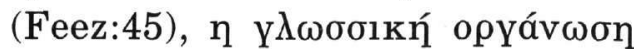

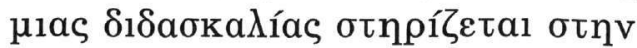

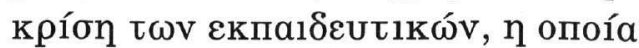

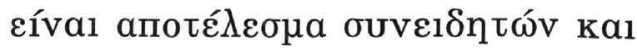

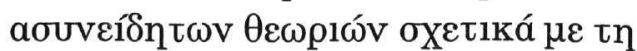

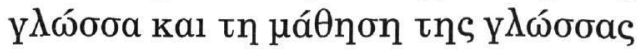




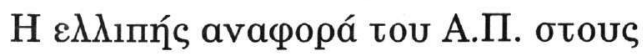

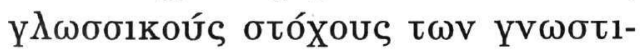

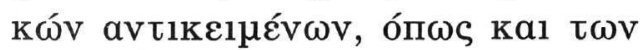

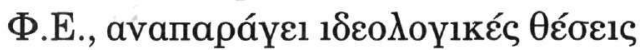

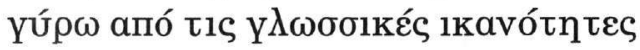

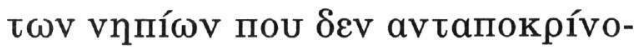

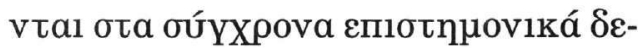

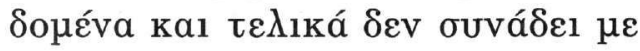

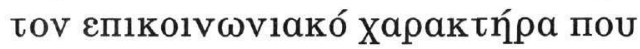

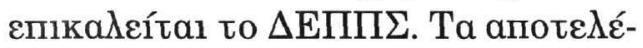

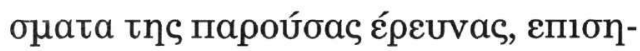

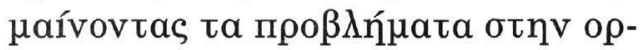

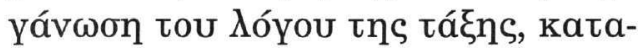

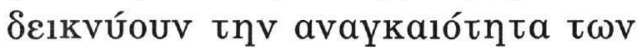

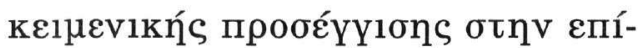

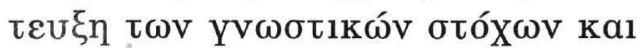

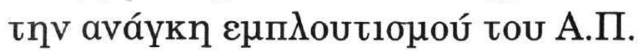

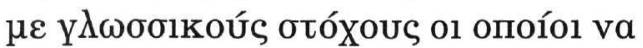

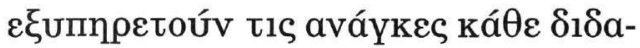
okalías.

\section{Bißגıүрачía}

Bakhtin, Medvedev, \& Voloshinov (1994). The Bakhtin Reader. London: Arnold.

Barnes, D. (1987). From communication to curriculum. London: Penguin Books.

Bathia, V. K. (1993). Analysing Genre: Language Use in Professional Settings. London: Longman.

Bernstein, B. (1974). Class, Codes and Control: Theoretical Studies Towards a Sociology of Language. London: Routledge and Kegan Paul.

Bernstein, B. (1990) The structure of Pedagogic Discourse. London: Routledge

Carey, S. (1985). Conceptual change in Childhood. Cambridge: MIT Press.

Christidou, B., \& Hatzinikita, B. (2006). Preschool Children's Explanation of Plant Growth and Rain Formation: A Comparative Analysis. Research in Science Education. 2005, 187-210

Christidou, B. (2005/2006) Accounting for Natural Phenomena. Explanatory Modes Used by Children. International Journal of Learning, 12, 21-28

Christie, F. and Martin, J. R. (Eds.) (1997). Genres and Institutions: Social process in the workplace and school [Open Linguistics]. London: Cassell.

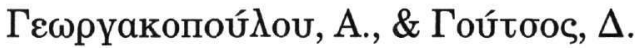

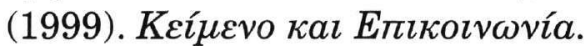

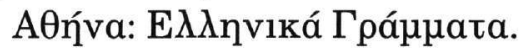

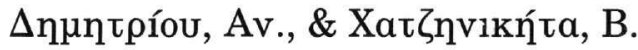

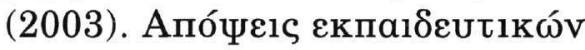

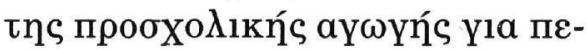

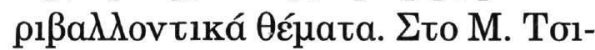

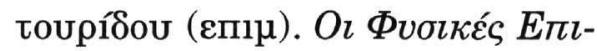

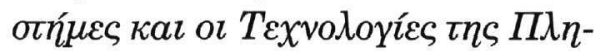

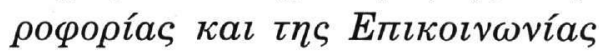

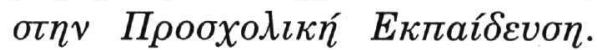

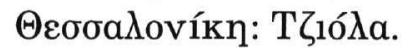

Eggins, S., \& Slade, D. (1997). Analysing Casual Conversation. London: Cassell.

Feez, S. (2002). Heritage and Innovation in Second Language Education. इto A. Johns: Genre in Classroom. Multiple Perspectives. Mahwah, New Jersey: Lawrence Erlbaum Associates.

Halliday, M.A.K. (1989). Spoken and written languge. Hong Kong: Oxford University Press. 
Halliday, M.A.K. (1989). "Part A.". In M.A.K. Halliday and Ruqaiya Hasan (eds). Language, context and Text: Aspects of language in a social-semiotic perspective. Oxford: Oxford University Press, 1-49.

Halliday, M.A.K. (1999). Н ү $\lambda \omega \sigma \sigma \alpha$

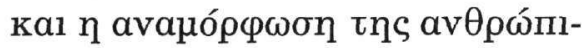

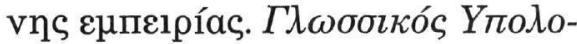
yıotís, 1. (http://www.komvos. edu.gr/periodiko)

Halliday, M.A.K. \& Martin, J. R.

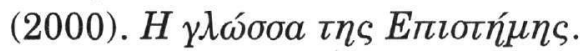
AӨท́va: Metaíxpıo.

Hyland, K. (2002). Genre: Language, Context and Literacy. Annual Review of Applied Linguistics 22: 113-135.

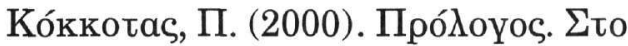
R. Driver, An. Squires, P. Rushworth \& V. Wood-Robinson:

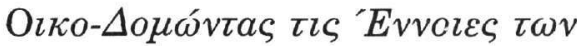

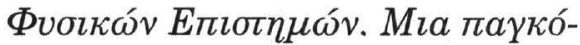

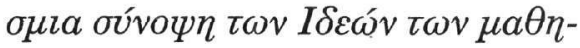

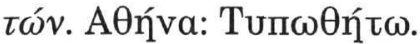

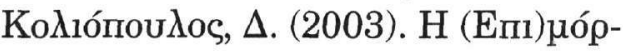

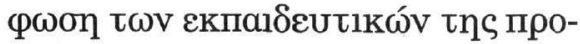

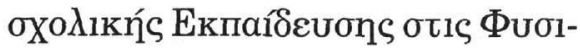

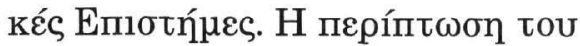

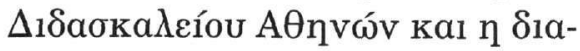

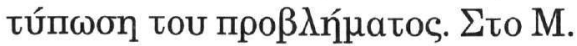

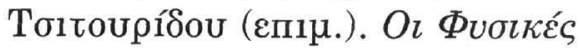

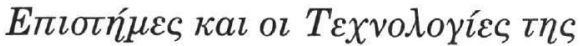

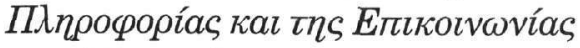

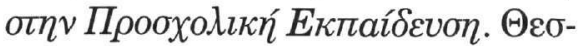
oaגovíkn: Tל̧ı́da.

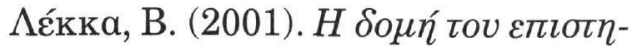

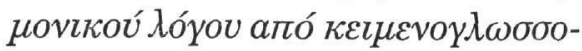

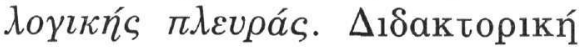

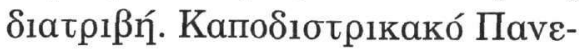

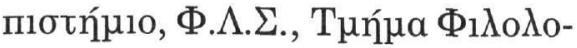

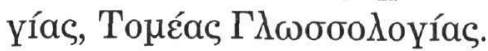

Lemke, J. (1990). Talking Science: Language, Learning and Values. New Jersey: Ablex Publishing.

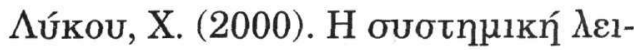

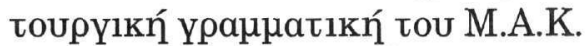

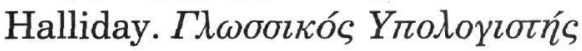
2: 57-71.

Macken-Horarik, M. (2002). "Something to shoot for": A Systemic Functional Approach to teaching Genre in Secondary School Science. In A. Johns (ed). Genre in the Classroom: Multiple Perspectives. N.J. \& London: Lawrence Erlbaum Associates, Publishers.

Martin, J.R. (1984). Types of writing in infants and primary school. In I. Unsworth (ed.) Reading, Writing, Spelling (Proceedings of the Fifth Macarthur Reading/ Language Symposium). Sydney: Macarthur Institute of Higher Education.

Martin, J.R. (1990). Literacy in science: learning to handle the text as technology. In F. Christie (ed.). Literacy for a Changing World. Melbourne: Australian Council for Educational Research (ACER), 79-117.

Martin, J.R. (1992). English Text: System and Structure. Amsterdam: Benjamins

Newkirk, T. (1984). Archimedes' dream. Language Arts 61(4)

Piaget, J. (1929). The Child's Conception of the World. London: Routledge and Kegan Paul

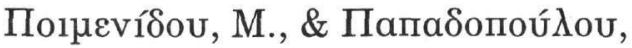

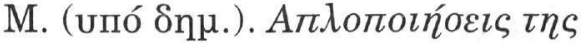

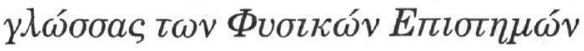




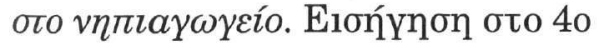

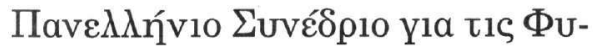

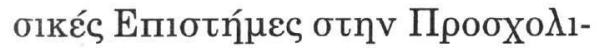
ки́ Ekпаíoevơn (23-25 Iouvíou

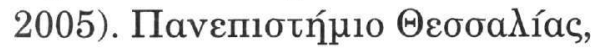
Bółoc.

Shea, N. (1988). The language of school science textbooks. BA Thesis. University of Sydney, Department of Linguistics.

Swales, J. (1990). Genre Analysis. Cambridge: Cambridge University Press

Tsatsaroni, A., Ravanis, K., \& Falaga, A. (2004) Studying the Recontextualisation of Science in Pre-school Classrooms: Drawing on Bernstein's Insights into Teaching and Learning Practices. International Journal of Science and Mathematics Education 1: 385-417.

Veel, R. (2000). Learning how to mean- scientifically speaking: apprenticeship into scientific discourse in the secondary school. In F. Christie \& J.R. Martin (eds.) Genre and Institutions. London: Continuum, 161-195.

\section{Abstract}

The paper explores the contribution of language in science activities. Recent Science Curriculums demand the use of specialized content, while structuring activities in the preschool Education. However, Greek pre-school Curriculum is characte- rized by the weak classification of knowledge and the lack of specific linguistic goals to support the structuring of the educational process.

The research deals with genres in the Science Curriculum and specifically with the sequential and causal explanation. After the collection of data, by means of videorecording science activities in nursery classroom, a discourse analysis model was applied, in order to reveal the way these genres unfold in the science activities. We will argue that a genre-based approach is a tool for selecting, organizing and evaluating educational activities.

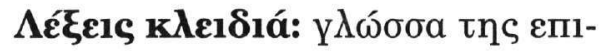

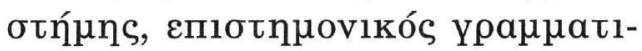

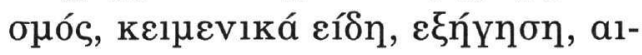

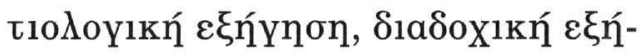
Yпon

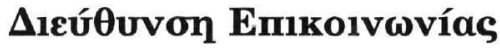

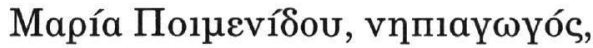

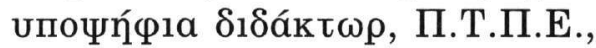

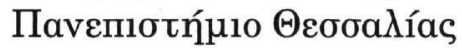

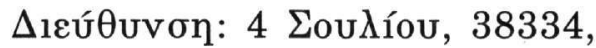
Bódos

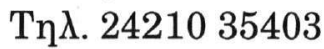

email:mpoimenidou@uth.gr

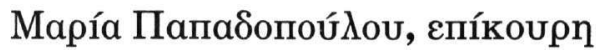

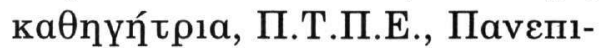

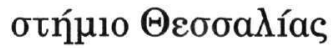

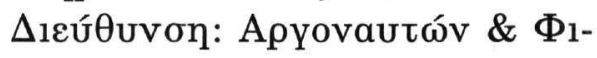
$\lambda \varepsilon \lambda \lambda \eta \underline{v \omega v}, 38221$ BóAos

$\operatorname{T\eta } \lambda .2421074750$

email:mariapap@uth.gr 